\title{
Room Temperature Mechanical Properties of Electron Beam Welded Zircaloy-4 Sheet
}

\author{
C. J. Parga, ${ }^{\text {a }}$ I. J. van Rooyen, ${ }^{\text {a* B. D. Coryell, }}{ }^{\text {b }}$ W. R. Lloyd, ${ }^{\mathrm{c}}$ L. N. Valenti, ${ }^{\mathrm{d}}$ and H. Usman ${ }^{\mathrm{e}}$
}

${ }^{a}$ Fuel Performance and Design Department, Idaho National Laboratory, Idaho Falls, ID 83415-6188, USA

${ }^{\mathrm{b}}$ Engineering Analysis Department, Idaho National Laboratory, Idaho Falls, ID 83415-6188, USA

${ }^{c}$ Materials Science and Engineering Department, Idaho National Laboratory, Idaho Falls, ID 83415-6188, USA

${ }^{d}$ Experiment Design and Analysis Department, Idaho National Laboratory, Idaho Falls, ID 83415-6188, USA

${ }^{\mathrm{e}}$ Mining Engineering Department, Faculty of Engineering, University of Syiah Kuala, Banda Aceh, Indonesia

*Corresponding author. Phone Number: +1 (208) 526-4199; Email: isabella.vanrooyen@inl.gov (I. J. van Rooyen)

\begin{abstract}
Resumption of operations at the Transient Reactor Test (TREAT) facility at Idaho National Laboratory was approved in 2014 to meet U.S. Department of Energy Office of Nuclear Energy objectives in transient testing of nuclear fuels. In parallel, the National Nuclear Security Administration, through the Office of Material Management and Minimization, is converting TREAT from its existing highly enriched uranium core to a low-enriched uranium core. This effort entails designing, fabricating, and qualifying a new TREAT low-enriched uranium fuel assembly, while maintaining TREAT's experimental performance capabilities. Zircaloy-4 is being evaluated as TREAT lowenriched uranium assembly material. A preliminary study on the room temperature mechanical properties of asreceived and electron beam welded Zircaloy-4 sheet $(1.6 \mathrm{~mm})$ is presented. The sheet was high-vacuum electron beam welded using a three-pass process with varying heat input: (1) tack welding (10.5 J/mm), (2) seams welded (36.7 J/mm), and (3) sealed (15.7 J/mm). As-received and electron beam welded specimens show comparable properties. Zircaloy-4 displays anisotropy between the transverse and longitudinal directions. Tensile properties measured for the transverse direction display higher yield strength, reduction of area, and slightly lower tensile strength and ductility than for the longitudinal (i.e., rolling) direction. Weld and base metal hardness are comparable, while hardness at the heat-affected-zone is slightly higher. Microscopic examinations show distinct microstructure morphology and grain size from weld to base metal. A correlation between welding parameters, mechanical properties, and microstructural features was established for electron beam welded Zircaloy-4 sheet.
\end{abstract}

KEYWORDS: TREAT LEU fuel conversion; Zircaloy-4; electron beam welding; mechanical properties; microstructure.

(C) 2016. This manuscript version is made available under the Elsevier user license http://www.elsevier.com/open-access/userlicense/1.0/ 


\section{INTRODUCTION}

The testing capacity of new fuel designs under transient conditions became more crucial after the Fukushima Dai-ichi Nuclear Power Plant site disaster in March 2011, because international focus was directed toward development of accident-tolerant fuels for light water reactors. These fuels are defined as nuclear fuel systems that can outperform current fuel systems (i.e., standard $\mathrm{UO}_{2}$-Zr-based alloy light water reactor fuel assemblies) during accident conditions (such as a loss-of-coolant accident) and maintain similar or higher performance during normal reactor operations, operational transients, and design-basis and beyond design-basis accidents. Zinkle et al. (2014) describes the three main strategies being pursued in regards to accident-tolerant fuels: (1) improvement of oxidation resistance of current zirconium alloy cladding, (2) replacement of zirconium alloys with alternative oxidationresistant high-performance cladding, and (3) replacement of monolithic ceramic oxide fuel with alternative fuel forms. Parga (2013) provides an extensive analysis on the aggressive environment experienced by fuel rods during a nuclear reactor severe accident based on the analysis of actual reactor core meltdowns (e.g., Three Mile Island-2, Chernobyl Reactor-4, and Fukushima Daiichi) and nuclear reactor safety tests.

In December 3, 2010, Peter B. Lyons (Assistant Secretary for Nuclear Energy, U.S. Department of Energy) approved the resumption of operations of the Transient Reactor Testing (TREAT) facility at Idaho National Laboratory (INL) in accordance with the requirements of the U.S. Department of Energy's program to resume the testing capacity of new fuel designs under transient conditions. TREAT is a uranium-oxide-fueled, graphite moderated, air-cooled reactor that is designed to produce controlled bursts of nuclear energy. TREAT first achieved criticality in 1959 and attained over 6,000 reactor startups. TREAT successfully operated during a 35-year period until its cold shutdown in 1994. The TREAT reactor is capable of producing very energetic power pulses $\left(2.4 \mathrm{GW} / \mathrm{sec}\right.$ ) and a high neutron flux (maximum equivalent integrated flux of $10^{16}$ neutrons $/ \mathrm{cm}^{2}$ ). TREAT can be controlled to emulate various operational modes and reactivity-insertion accidents via shaped transients without causing any damage to its core.

During the 35th International Meeting on a Reduced Enrichment for Research and Test Reactors, van Rooyen et al. (2014) stated that in parallel with the TREAT reactor restart program, the National Nuclear Security Administration (NNSA) is developing a replacement of the TREAT highly enriched uranium fuel core (U-235 > 90 wt.\% U) with a low-enriched uranium (LEU) core (U-235 < $20 \mathrm{wt} . \% \mathrm{U})$. This effort entails designing the new 
TREAT LEU fuel, integrating with the original highly enriched uranium fuel assembly interface dimensions, and implementing modern fabrication techniques, while maintaining prior operational and testing capabilities.

The TREAT fuel assembly comprises a central, rectangular-shaped fuel block section made of a graphitic matrix with finely dispersed uranium oxide granulates, along with two graphite reflector blocks on the extremes of the columnar configuration. The graphitic section is encased in a metallic cladding that protects the fuel blocks from the exterior atmosphere, keeps fission gases contained, and aids the conduction of heat produced by fission.

Drawings of TREAT's original, upgraded, and conceptual LEU fuel assembly are presented in Figure 1.

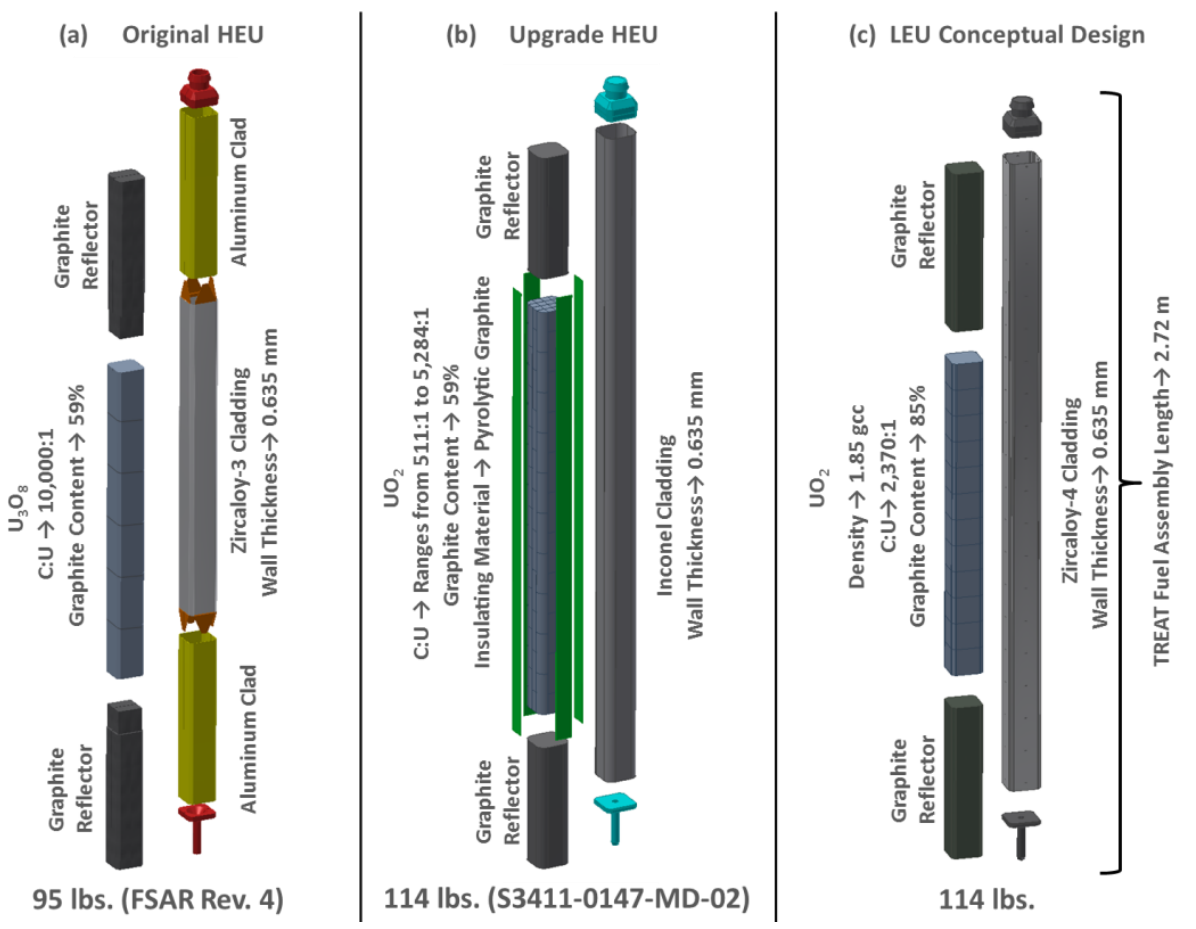

Figure 1. TREAT reactor fuel assembly's main components of (a) original, (b) upgraded highly enriched uranium assembly, and (c) draft conceptual LEU fuel element (adapted from van Rooyen et al. 2014).

Among the objectives of the fuel engineering and design team at INL is the preliminary evaluation of various TREAT LEU assembly designs, materials, fabrication techniques, and their performance. This information is essential for down selection and further qualification of mockup assemblies that will serve as the basis to fabricate the final TREAT LEU core assemblies. Among various areas of analysis, the mechanical property assessment of candidate nuclear cladding materials, studies on fuel-clad-coolant chemical interaction, cladding weldability, and formability into desired shapes are of importance for the project. 
Zirconium (Zr)-based alloys are widely used in the nuclear and chemical industry due to their very low thermal neutron absorption cross section $\left(\Sigma_{\mathrm{a}}=0.008 \mathrm{~cm}^{-1}\right)$ and good corrosion resistance. Krishnan and Asundi (1981) explains that Zr-based alloys were initially selected and developed as structural materials for U.S. naval nuclear reactors, and the Mark II naval reactor later became the design basis for the widely deployed pressurized water reactors. Comstock and Barberis (2015) compiles state-of-the-art $\mathrm{Zr}$ technology during the 17th International Symposium on $\mathrm{Zr}$ in the Nuclear Industry, reaffirming the continued importance of $\mathrm{Zr}$ in the nuclear sector. Conversely, studies on the microstructure and mechanical properties of Zircaloy-4 (Zr-4) joined via electron beam welding (EBW) are very scarce in technical literature because Zr-4 is commonly used as a seamless tube rod (OD: $\sim 1 \mathrm{~cm}$ ) for nuclear reactor fuel cladding in pressurized water reactors. These tubes are usually formed through drawing and spinning techniques, quite different to TREAT's fuel columnar assembly design (square cross-section: $\sim 10 \times 10 \mathrm{~cm}$ ). Some studies are available on the properties of EBW pure Zr, hafnium-containing Zr-alloys (Zr-702), and distinct nuclear-grade $\mathrm{Zr}$ alloys (Zircaloy-2 and $\mathrm{Zr}-2.5 \mathrm{Nb}$ ). However, welding parameter and mechanical property evaluation of EBW Zr-4 alloy is seldom found in technical literature. For example, Tomie et al. (1990) present limited results on the weld joint characteristics of the EBW Zr plate for large-scale manufacture of pressure vessels used in the chemical industry. Milosavljevič (1962) found that optimization of parameters for EBW of Zr-2 tubes reduces heat effects on the weld region's physico-metallurgical properties and reduces weld contamination when compared to gas tungsten arc welding. Semenov et al. (2013) discovered that by optimizing the EBW heat source, the corrosion resistance of weld joints between $\mathrm{Zr}-2.5 \mathrm{Nb}$ and steel using a $\mathrm{Zr}-1 \mathrm{Nb}$ filler material is slightly improved when compared to complicated traditional post-weld thermomechanical treatments. Zhang et al. (2015) conclude that EBW of Zr-702 actually improved the corrosion resistance of the joint region because less pitting was observed at the weld when compared to the heat-affected zone (HAZ) and base metal. Suzuki et al. (1962) found that EBW of $\mathrm{Zr}$ and $\mathrm{Zr}-2$ sheet produces weld joints with better mechanical properties and corrosion resistance in high-temperature-pressure water than gas tungsten arc-welded specimens. Similar observations on the favorable properties of EBW Zr-4 are presented hereafter.

This article presents the preliminary results on room temperature mechanical testing of EBW and as-received Zr-4 sheet material. Zr-4 material specifications and welding parameters will be presented. Evaluation of mechanical properties (i.e., elasticity, ductility, yield, and tensile strength) obtained via tensile testing and nanohardness/Vickers microhardness measurements (i.e., at the weld, HAZ, and base metal), along with optical and electron microscopy 
studies at the weld region, will be presented to establish a correlation between the welding-microstructure-property of sheet specimens.

\section{EXPERIMENTAL}

\subsection{Material and Welding Specifications}

The Zr-4 sheet with 1.6-mm thickness was obtained from ATI Wah Chang (Heat 250967, Batch 219068).

Table 1 presents the parent $\mathrm{Zr}-4$ ingot chemical composition analyzed by alpha particle $\mathrm{x}$-ray spectrometry and provided in the product certification sheet.

Table 1. Chemical composition of $\mathrm{Zr}-4$ ingot.

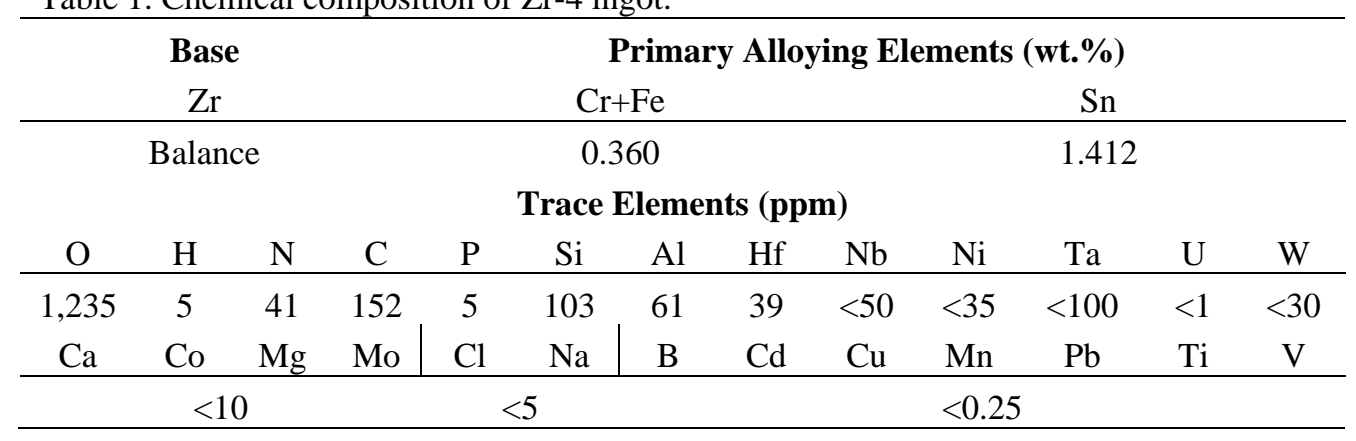

Weldment and base metal tensile specimens were sectioned from a $\mathrm{Zr}-4$ sheet piece $(27.6 \times 114.3 \times 0.16 \mathrm{~cm})$. Figure 2a shows a sheet section where base metal specimen blanks were taken. Figure $2 \mathrm{~b}$ shows the detail of the right end of the sheet shown in Figure 2a, identifying the location and orientation of the base metal tensile specimen blanks. "L" specimen blanks are parallel to rolling direction; "T" specimen blanks are perpendicular or transverse relative to the rolling direction. Sheet portion utilized for EBW was previously removed from the right end of the sheet (see Figure 2). 


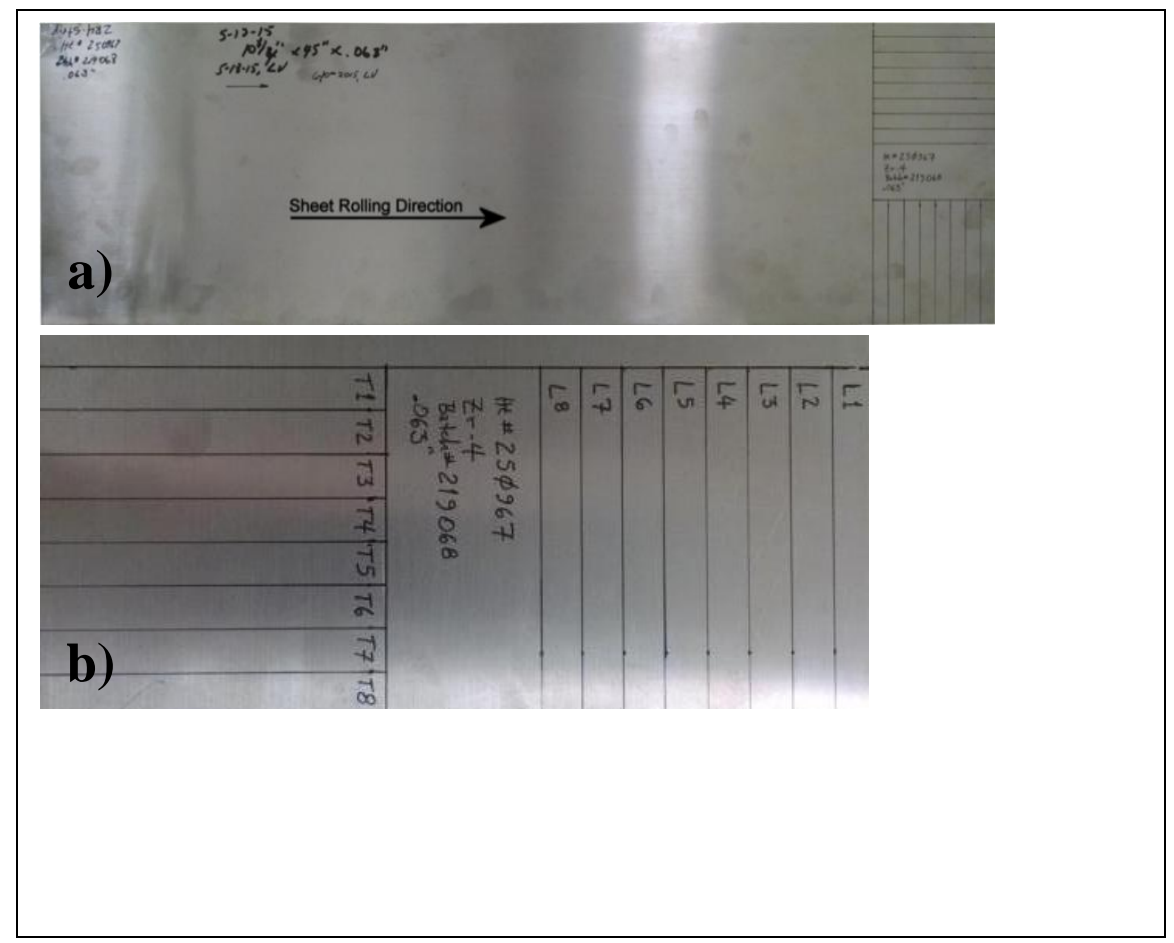

Figure 2. (a) Original Zr-4 sheet showing rolling direction and relative location of base metal tensile specimen removal. (b) Base metal tensile specimen blank cutting layout (rolling direction parallel to "L" specimen length). The weldments were made at Sciaky, Inc. facilities in Chicago, Illinois using a Sciaky VX.1 EBW machine (8-kW power rating, $60-\mathrm{kV}$ maximum accelerating voltage, and a high vacuum system). Parametric investigation welds (e.g. bead on plate, no joint) were made with various beam parameters to optimize the resulting weldment. Pieces of material for the weld study and test weldment were obtained from the same sheet (i.e., same heat and batch) as the base metal tensile specimens. The fixture was cleaned and degreased to remove any oil residues or contamination/dirt. The plate was completely cleaned with acetone and then ethanol using a lint-free cloth. Beam current, focus current, and weld speed were varied in order to achieve a satisfactory weld with nominally $100 \%$ weld penetration. Once the optimal parameters were established, a sheet section approximately $23 \times 20 \mathrm{~cm}$ was sheared in half parallel to the rolling direction, yielding the two halves to be joined by EBW. The area within $50 \mathrm{~mm}$ of the weld was cleaned again with acetone and ethanol using a lint-free cloth. The pieces were placed in a butt joint configuration and assembled in the fixture as observed in Figure 3a; then they were placed inside the EBW chamber for welding (Figure 3b). Table 2 provides details about the welding specifications utilized for the EBW process. The electron beam parameters of the "three-pass" EBW process are provided in Table 3. 


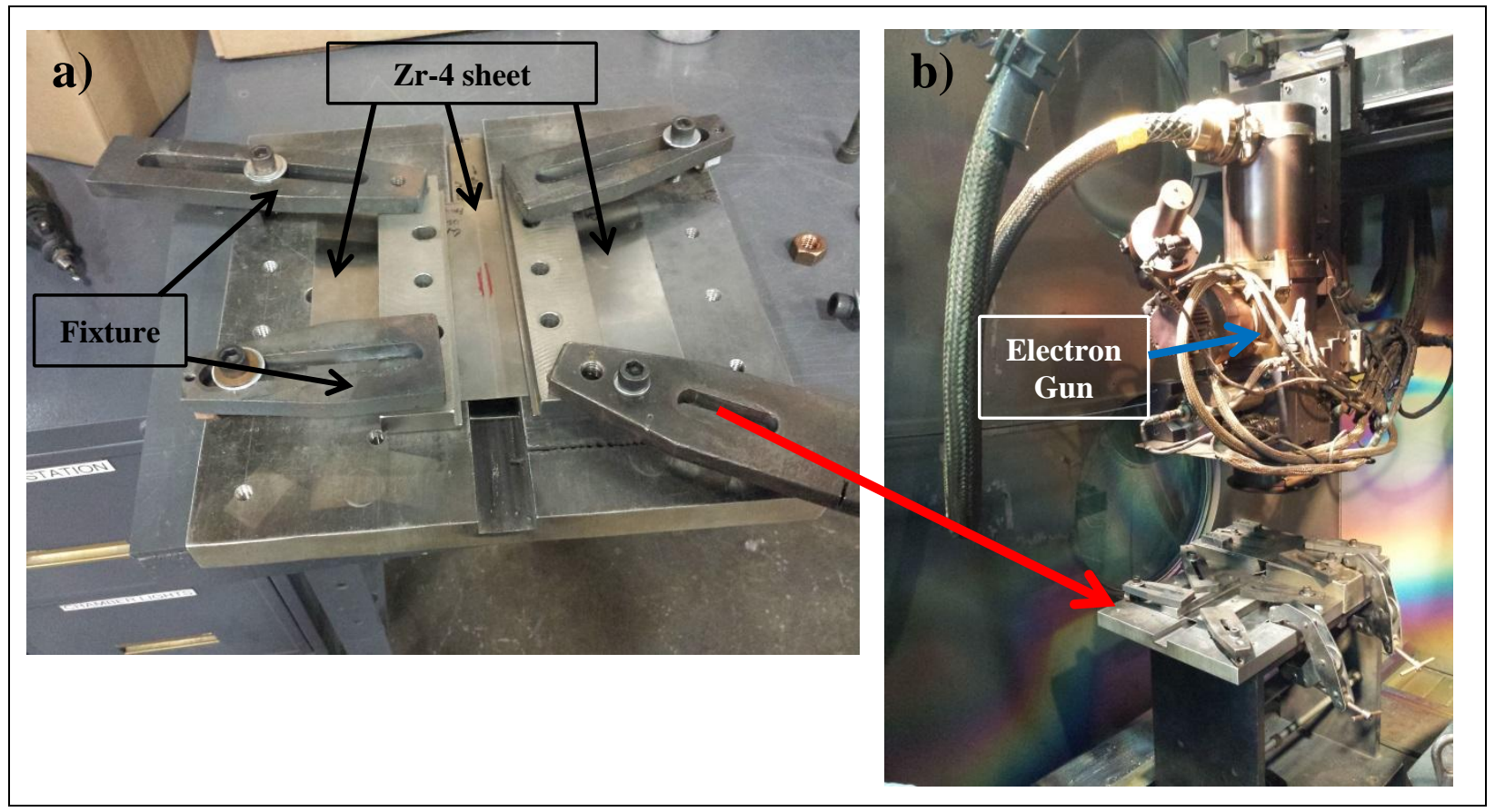

Figure 3. (a) Zr-4 sheet held in place by fixture (b) and fixture assembly placed inside EBW chamber.

The workpiece was allowed to cool down to room temperature between passes, while the input parameters of the next pass were introduced and the electron gun was repositioned using the W2020 computer numerical control joint scanning and digitizing system. Finally, after the welding cycle was terminated, the work was kept in the chamber and allowed to cool down to room temperature before allowing air back into the chamber. This was a first attempt at EBW Zr-4 sheet material; welding parameters will be further refined and the mechanical and microstructural evaluation expanded during the welding qualification process.

Table 2. Welding specifications for $\mathrm{Zr}-4$ sheet $(1.6 \mathrm{~mm})$.

\begin{tabular}{l}
\hline \multicolumn{1}{c}{ Welding Variables } \\
\hline Groove Design \\
Backing \\
Fit-up Gap \\
Material \\
Penetration \\
Filler Metal \\
Preheat \\
Post Welding Heat Treatment \\
Environment \\
Electrical Characteristics \\
Pulsing Frequency \\
Oscillation \\
Angle of Beam Axis \\
Equipment Type \\
Vacuum Pressure \\
Pass/es
\end{tabular}

Values

Square groove with butt joint None

$<0.13 \mathrm{~mm}$

Zircaloy-4 (UNS R60804)

$100 \%$ penetration (1.6 mm thick sheet)

None (Autogenous weld)

Welded at room temperature $\left(20-25^{\circ} \mathrm{C}\right)$

$$
\text { None }
$$

High vacuum, no protective gas used

See Table 3

Continuous

None

$90^{\circ}$ (perpendicular to workpiece)

Sciaky VX.1 EBW (8-kW, 60-kV, high vacuum)

$13.3 \mathrm{mPa}$

Three-pass (Tack, Weld, Seal) 
1 or 2 side welding

Use of Thermal Processes

One side welding

N/A

Table 3. EBW parameters for $\mathrm{Zr}-4$ sheet $(1.6 \mathrm{~mm})$ "three-pass" process.

\begin{tabular}{cccccccc}
\hline Weld & $\begin{array}{c}\text { Accelerating } \\
\text { Pass }\end{array}$ & $\begin{array}{c}\text { Beam } \\
\text { Vurrent, } \\
\mathbf{m A}\end{array}$ & $\begin{array}{c}\text { Beam } \\
\text { Spot } \\
\text { Size, } \boldsymbol{\mu m}\end{array}$ & $\begin{array}{c}\text { Beam } \\
\text { Travel } \\
\text { Speed } \\
\mathbf{m m} / \mathbf{s}\end{array}$ & $\begin{array}{c}\text { Gun-to- } \\
\text { Work } \\
\text { Distance } \\
\text { mm }\end{array}$ & $\begin{array}{c}\text { Beam } \\
\text { Power } \\
\text { kW }\end{array}$ & $\begin{array}{c}\text { Heat } \\
\text { Input } \\
\text { J/mm }\end{array}$ \\
\hline Tack & 40 & 10 & 363 & 38.1 & 203 & 0.4 & 10.5 \\
Weld & 40 & 35 & 380 & 38.1 & 203 & 1.4 & 36.7 \\
Seal & 40 & 15 & 357 & 38.1 & 203 & 0.6 & 15.7 \\
\hline
\end{tabular}

The resulting weldment was returned to INL for evaluation and preliminary tests. Slight deformation or angular distortion $\left(\alpha \leq 1^{\circ}\right)$ resulted from the welding process, because it can be observed in the optical micrograph presented in Subsection 3.1. Radiography of the welded sheet was performed to check for weld defects (see Figure 4). Most of the weld defects are observed on the right-side of the sheet, where the welding started. It seems that, initially, the "key-hole" could not be stabilized and it kept collapsing and producing weld defects because of a lack of fusion and some porosity entrapped in the weld joint. These defects can be caused by instabilities or turbulence in the molten metal that altered the balance of forces between the liquid-vapor-solid and the hydrostatic pressure, which are essential for formation of an adequate weld joint. As the electron beam progressed along the central part of the sheet, the "key-hole" stabilized and did not show apparent defects in this region. The last section of the seam (i.e., the left part of the sheet) shows incomplete penetration, which was probably caused by lack of a runaway piece and/or no electron beam speed reduction during welding of the final section of the sheet. Schultz (1994) provides a more indepth description on the behavior of an electron beam penetrating a metal and the weldability of metallic materials. The location of the weld tensile specimens and metallographic analysis/hardness measurement sample (i.e., "Met specimen") were selected to avoid identified weld defects so the test results would be representative of "good" weldments (see Figure 5). 


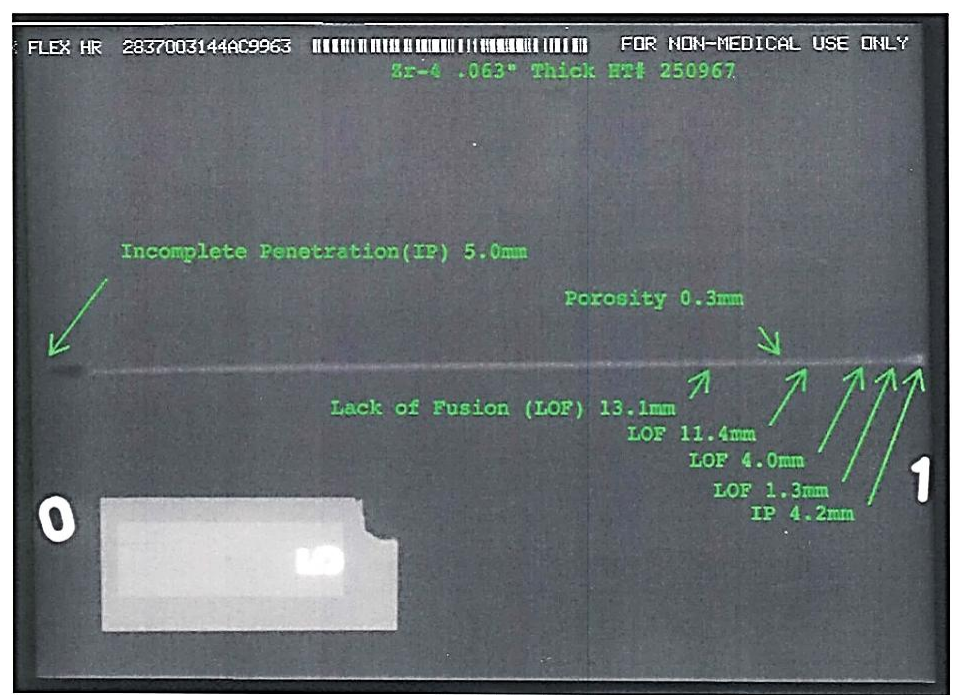

Figure 4. Radiograph of Zr-4 sheet showing some weld defects along the seam.

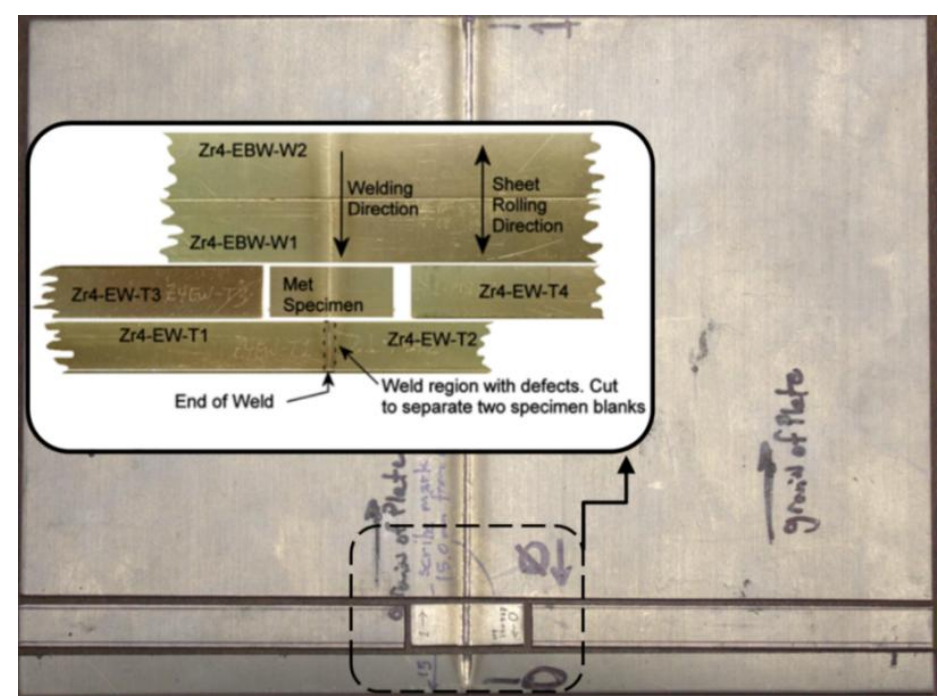

Figure 5. Zr-4 sheet showing EBW seam along the rolling direction and sectioned specimens.

\subsection{Nano-Hardness and Vickers Microhardness Test Details}

A section of the EBW sheet about 7-mm wide (i.e., parallel to the weldment) was removed for assessment (see "Met specimen" in Figure 5). The resultant sample was hot-mounted in powder phenolic resin to present the weld cross section (1.6-mm nominal thickness) for preparation and examination. Mounting and subsequent nanohardness scans were completed at INL's Center for Advanced Energy Studies. The mounted sample was prepared by sequential wet abrasive grinding on 320;600; 1,000; and 1,200-grit silicon carbide papers and was finished by vibratory-polishing using an aqueous suspension of $0.01-\mu \mathrm{m}$ alumina. The polished specimen was etched at room temperature by swabbing the weld region with an aqueous solution consisting of $22-\mathrm{ml}$ of $\mathrm{H}_{2} \mathrm{O}, 22 \mathrm{ml} \mathrm{HNO}_{3}$, and 3 
$\mathrm{ml} \mathrm{HF}$ to reveal grain boundaries and to allow the weld metal and HAZ boundaries to be delineated (prepared at INL's Research Center Metallography Laboratory). Optical and scanning electron microscopy (SEM) were used to examine the weld region and microstructural features.

The nanohardness test was performed with a TI 950 TriboIndenter manufactured by Hysitron. The machine is affixed to a granite table and located inside a chamber under a controlled environment. The instrument supports numerous nanomechanical characterization techniques and has a digital data acquisition system. A Berkovich indenter (i.e., three-sided pyramid indenter with a 1- $\mu \mathrm{m}$ tip radius) was utilized to measure the hardness of the sample. The distance between indents was $60 \mu \mathrm{m}$ apart (approximately $2 \mathrm{x}$ the indent diameter) with a 1-minute indentation hold time at the maximum load. Before beginning the test, calibration was performed using a standard fused quartz sample. Initially, a series of nanohardness measurements with varying load were performed to explore the indentation force effect on measurement variability to establish an appropriate maximum load for subsequent hardness testing. These measurements consisted of performing five indentations per load at five different loads ranging from 50 to $500 \mathrm{mN}$ on the as-received $\mathrm{Zr}-4$ sheet. A 500-mN target force was selected in order to increase the penetration depth into the metal (i.e., h greater than $5 \mu \mathrm{m}$ ). The nanohardness scan consisted of an indentation grid comprising 1,425 points ( 25 rows by 50 columns at $60-\mu \mathrm{m}$ intervals). The scan covered the entire weld region and base metal on both sides of the weld. The transverse (x) measuring positions spanned $3.4 \mathrm{~mm}$, starting in base metal about $1.92 \mathrm{~mm}$ from the weld centerline and ending about $1.48 \mathrm{~mm}$ on the opposite side of the centerline. The through-sheet-thickness (y) measuring positions spanned $1.44 \mathrm{~mm}$, with the distance to the upper and lower surfaces from the closest hardness test points ranging between 60 and $100 \mu \mathrm{m}$.

A Vickers microhardness scan was performed with a Zwick Type B2212001 machine to complement the nanohardness test. Calibration was performed using a standard metallic test block. The error range on the microhardness measurements was $\pm 10 \mathrm{HV}$. A 200-gram load was utilized to perform 120 micro-indents (i.e., 5 rows by 12 columns at $250-\mu \mathrm{m}$ intervals) spanning $5.7 \mathrm{~mm}$ in the transverse (x) direction, covering an approximate length of $2.85 \mathrm{~mm}$ from the weld centerline into the base metal, and $1 \mathrm{~mm}$ in the through-sheet-thickness (y) direction, with an approximate $300-\mu \mathrm{m}$ distance to the upper and lower surfaces.

\subsection{Tensile Test Details}


An Instron Model 5582 test machine was used to conduct the room temperature (i.e., 23 to $24^{\circ} \mathrm{C}$ ) tensile tests of the $\mathrm{Zr}-4$ material, including base metal in both the longitudinal and transverse orientations, and specimens with a transverse weld across the center of the reduced section. Tensile testing was performed in accordance with American Society of Testing and Materials (ASTM) Standard Method E8/E8M-13. A calibrated, 100-kN load cell and extensometer with a 25.4-mm gauge length and $10 \%$ engineering strain measuring range was used to measure engineering strain in the specimens during the tests. The extensometer was calibrated prior to each test in accordance with ASTM Standard Method E83 using a National Institute of Standards and Technology-traceable calibration reference instrument and it met accuracy class B2 for each calibration as required by E8 for $0.2 \%$ offset yield strength determination.

Test specimen blanks were shear cut from the $\mathrm{Zr}-4$ sheet. Two samples (i.e., transverse to rolling direction and welding axis) were removed from the $\mathrm{Zr}-4 \mathrm{EBW}$ weldment section following the met specimen (Figure 5).

The tensile test specimens are identified according to the following:

- $\quad$ Specimen loading axis parallel to the sheet rolling (i.e., longitudinal) direction: ZR4-Lx.

- $\quad$ Specimen loading axis perpendicular to the sheet rolling (i.e., transverse) direction: ZR4-Tx.

- $\quad$ Specimen includes a transverse electron beam weld: ZR4-EBW-Wx.

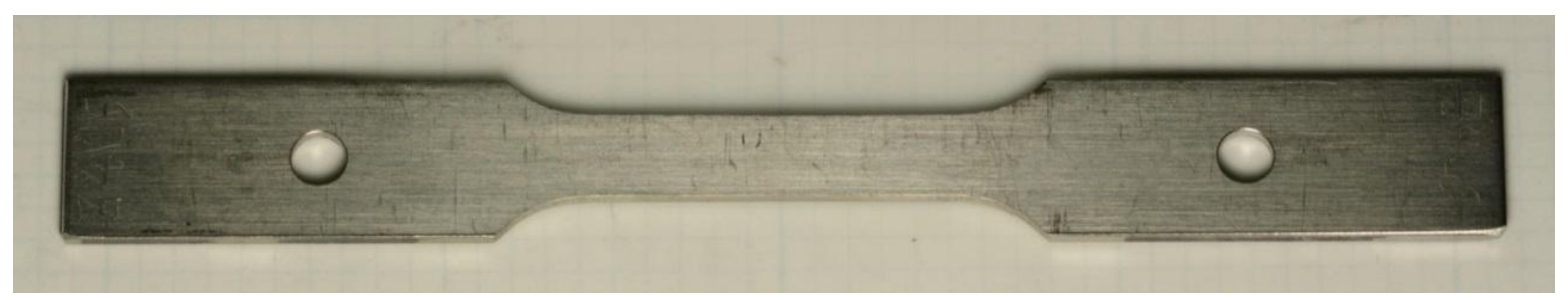

Figure 6. Representative Zr-4 subsized sheet tensile testing specimen [ASTM E8].

The rectangular specimen blanks were fabricated into ASTM E8 subsized sheet specimens (see Figure 6) using a TensilKut specimen fabrication machine. Detailed specimen dimensions are presented in Table 4. The edges of the specimen-reduced sections were hand-finished using abrasive paper (280 to 400 grit SiC) wrapped around a small rigid cylinder and using a jig that maintained the perpendicularity of the edges with the specimen faces and prevented rounding of the corners in the reduced section region. Each specimen's width and thickness was measured at multiple locations along the length of the reduced section using calibrated instruments suitable for the dimension measured. The dimensions at the location of the minimum cross-section area in each specimen are used for the stress 
calculations. Width and thickness measurements represent the average of at least three independent measurements. A dual-point gauge mark indentation punch was used to put precisely spaced conical indents in the reduced section of each specimen; this allowed post-test ductility values to be determined (indents are on the order of $250-\mu \mathrm{m}$ diameter and about $150-\mu \mathrm{m}$ deep). Overall length is recorded to use as an alternative ductility calculation method in the event the gauge marks are obscured by plastic deformation during testing.

Table 4. Subsized tensile test specimen dimensions.

\begin{tabular}{lcccc}
\hline Specimen & Overall Length, mm & Width, mm & Thickness, mm & Gauge Length, mm \\
\hline Zr4-L1 & 108.60 & 6.422 & 1.603 & 25.426 \\
Zr4-L2 & 108.77 & 6.429 & 1.607 & 25.423 \\
Zr4-L3 & 108.65 & 6.433 & 1.612 & 25.425 \\
Zr4-T1 & 108.60 & 6.395 & 1.628 & 25.426 \\
Zr4-T2 & 108.47 & 6.375 & 1.626 & 25.426 \\
Zr4-T3 & 108.38 & 6.450 & 1.630 & 25.424 \\
ZR4-EBW-W1 & 106.98 & 6.371 & 1.623 & 25.424 \\
ZR4-EBW-W2 & 107.67 & 6.396 & 1.627 & 25.423 \\
\hline
\end{tabular}

\subsection{Characterization}

SEM model JEOL JSM-6610 LV (low-vacuum chamber and 20-kV accelerating voltage) was used in the secondary electron and backscattered electron mode to analyze the weld surrounding area and microstructure of the etched samples. Samples were previously mounted in conductive resin, ground, polished, and etched as explained in Subsection 2.2. The samples were directly placed into the vacuum chamber of the SEM and appropriate magnification was used to capture the micrographs. Optical microscopy was utilized in consonance with electron microscopy to analyze the weld region's grain size variations and microstructure morphology.

\section{RESULTS AND DISCUSSION}

\subsection{Weld and Heat-Affected Zone Boundary Calculation}

During welding, heat flow in a workpiece of enough length is steady, or quasi-stationary, with respect to the moving heat source, except for the initial and final welding transients. This means that from the perspective of the heat source, the temperature distribution and weld pool geometry do not change with time. Rosenthal (1941) used steady-state assumptions to simplify the mathematical treatment of heat flow during welding and derive analytical 
equations for (1) steady-state heat flow, (2) point heat source, (3) negligible heat of fusion, (4) constant thermal properties, (5) no heat losses from the workpiece surface, and (6) no convection in the weld pool. The analytical solution derived by Rosenthal for three-dimensional heat flow in a semi-infinite workpiece during welding is as follows:

$$
\frac{2 \pi\left(T-T_{\mathrm{o}}\right) k R}{Q}=\exp ^{\left[\frac{-V(R-x)}{2 \alpha}\right]}(1)
$$

where:

$\mathrm{T}=$ temperature

$\mathrm{T}_{\mathrm{o}}=$ workpiece temperature before welding

$\mathrm{k}=$ workpiece thermal conductivity

$Q=$ heat transferred from heat source to workpiece, namely, $\eta E I$, where $\eta, E$ and I are heat source efficiency, voltage, and constant current, respectively.

$V=$ welding speed

$\alpha=$ workpiece thermal diffusivity, namely, $k / \rho C_{p}$, where $\rho$ and $C_{p}$ are density and specific heat of the workpiece, respectively

$R=$ radial distance from origin, namely, $\left(x^{2}+y^{2}+z^{2}\right)^{1 / 2}$.

Table 5. Thermal properties for Zr-4 (ATI Wah Chang 2003).

\begin{tabular}{lc}
\hline Material & $\mathrm{Zr}-4$ (UNS R60804) \\
Density, $\boldsymbol{\rho}, \mathbf{g} / \mathbf{c m}^{\mathbf{3}}$ & 6.55 \\
Specific Heat Capacity, $\boldsymbol{C}_{\boldsymbol{p}}, \mathbf{J} / \mathbf{g} \cdot \mathbf{K}$ & 0.285 \\
Thermal Conductivity, $\boldsymbol{k}, \mathbf{W} / \mathbf{m} . \mathbf{K}$ & 21.5 \\
Melting Temperature, $\boldsymbol{T}_{\boldsymbol{m}},{ }^{\circ} \mathbf{C}$ & 1850 \\
Thermal Diffusivity, $\boldsymbol{\alpha}, \mathbf{~ m}^{2} / \mathbf{s}$ & $1.1 \times 10^{-5}$ \\
\hline
\end{tabular}

Rosenthal's analytical equation (Equation 1) was used to calculate the weld and HAZ boundary (Figure 7). The thermal properties of $\mathrm{Zr}-4$ (Table 5), the welding parameters (Table 3) and a corresponding 0.8 value for the heat source efficiency were utilized to calculate the isotherms presented in Figure 8 . The thermal properties for $\mathrm{Zr}-4$ (Table 5) were assumed constant and independent of temperature. Equation 1 was used to calculate the steady-state temperature $T(x, y, z)$, with respect to the moving heat source, at the surface $(z=0)$ of the workpiece $(x, y, z)$. The fusion boundary and outer boundary of the HAZ isotherms are semicircular in shape (isotherm $T$ on a plane at a given $x$ has a radius of $R$ ) on the transverse cross section of the weld. The weld boundary width was calculated at 2.4 $\mathrm{mm}$ and is defined by the $1850^{\circ} \mathrm{C}$ isotherm that corresponds to the $\mathrm{Zr}-4$ melting point. The calculated value is approximately $6 \%$ higher than the measured valued of the weld width (i.e., $2.26 \mathrm{~mm}$; Figure 7) ("Met specimen" weld cross-section), which is remarkably close considering a 5\% measurement error. The measured HAZ width value is $3.2 \mathrm{~mm}$ (Figure 8 ) and corresponds to the $1000^{\circ} \mathrm{C}$ isotherm or $0.6 \mathrm{~T}_{\mathrm{m}}$ of the alloy's absolute melting 
temperature. Because the HAZ boundary isotherm represents the extent of the heat effect in the microstructure, it correlates well (within experimental accuracy) with experimental observations of the increase in self-diffusion of metallic species as a result of the activation of alternate diffusion mechanisms at high temperatures (about $0.66 \mathrm{~T}_{\mathrm{m}}$ or two-thirds of the absolute melting temperature). Mehrer (2007) provides experimental data and an explanation about the observed three-fold increase in diffusivity at higher temperatures for allotropic materials as $\mathrm{Ti}, \mathrm{Zr}$, and $\mathrm{Hf}$, after undergoing hexagonal closed packed (HCP) to body centered cubic (BCC) lattice structure transformation due to the relatively fast self-diffusion in the less densely packed BCC lattice when compared to HCP. Semenov et al. (2013) measured the temperature distribution around the weld via thermocouple and pyrometer measurements during studies performed on EBW heating source optimization while welding zirconium pipes. The temperature profiles recorded in their study correlate well with the weld solidification profile observed in this study.

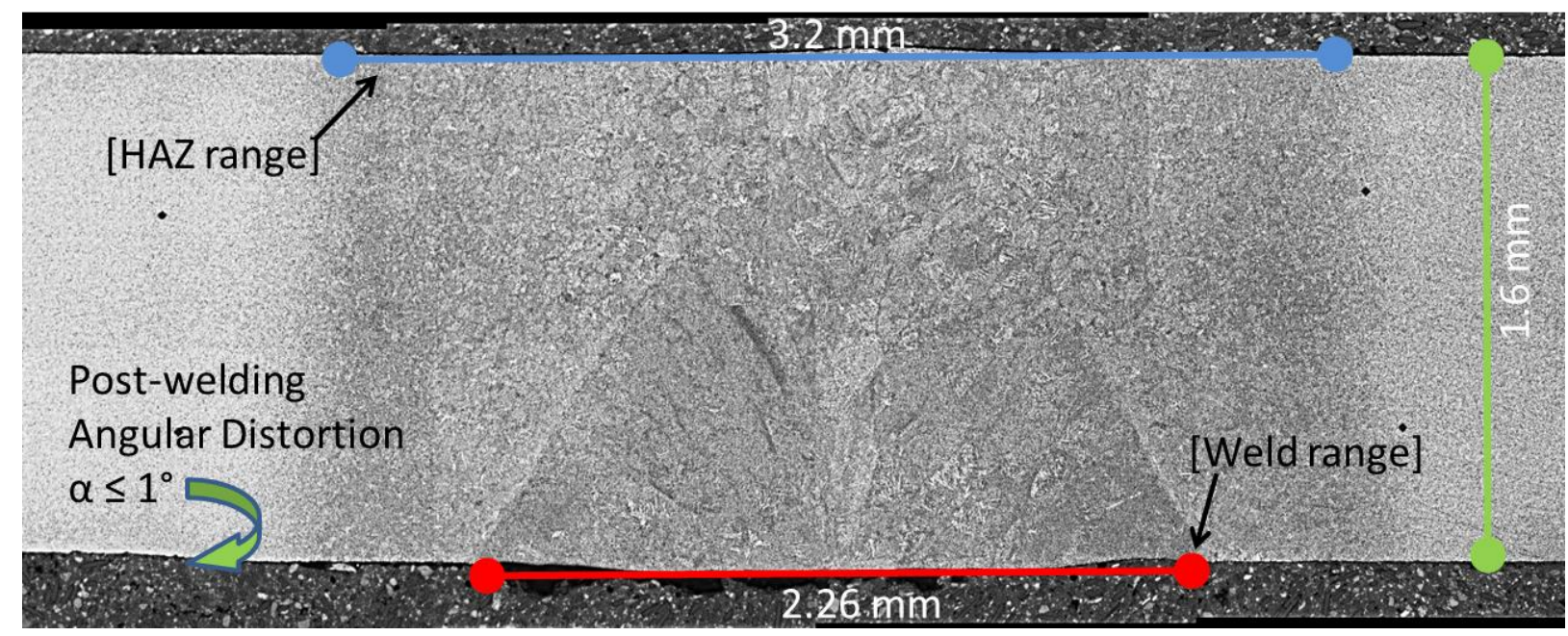

Figure 7. Weld cross section showing post-weld angular distortion, fusion zone, and HAZ width. 


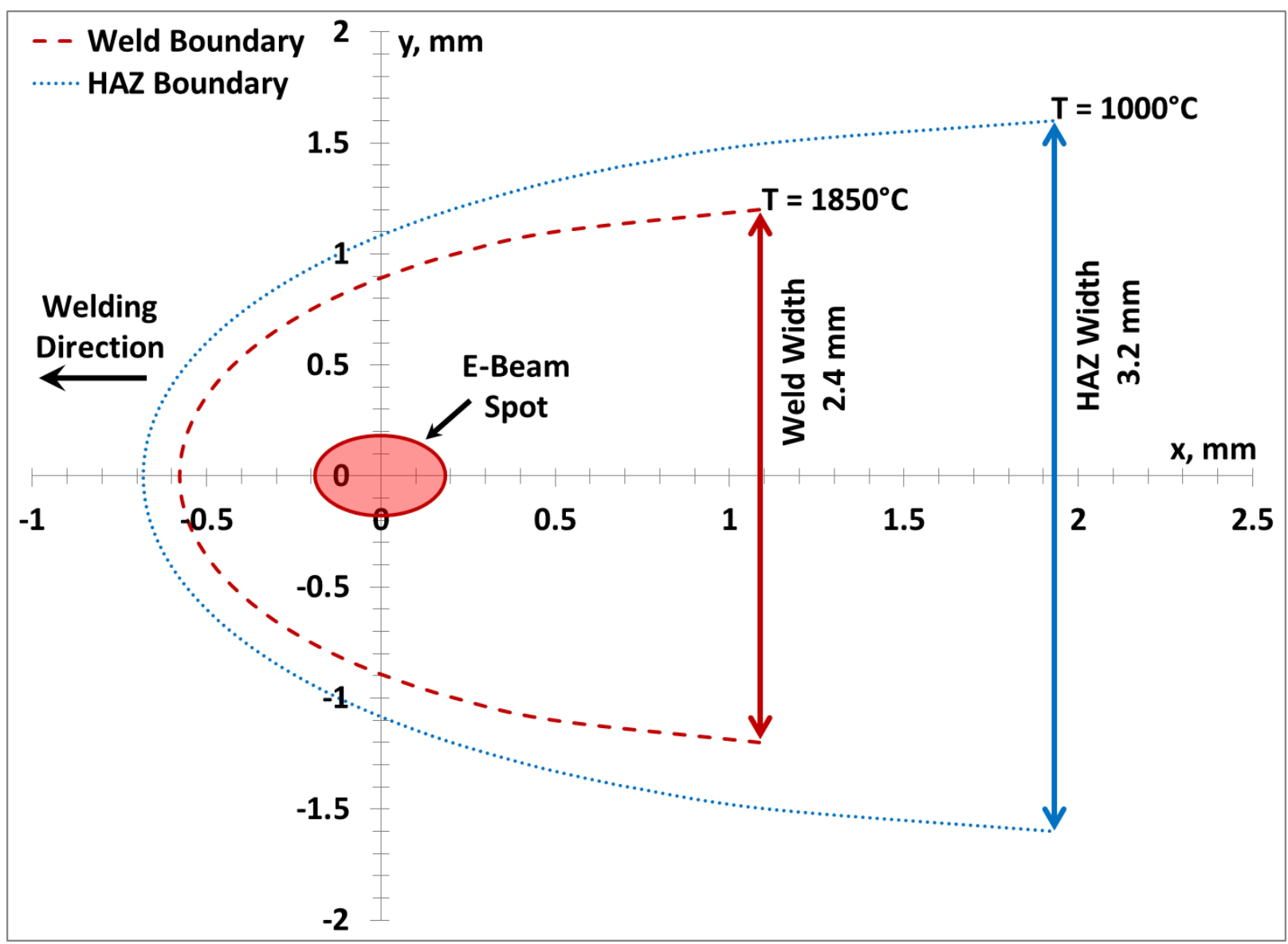

Figure 8. Sheet surface weld and HAZ boundary calculated with Rosenthal's three-dimensional heat flow equation.

\subsection{Tensile Test}

Results of the tensile tests of Zr-4 sheet (base metal) in longitudinal (L) and transverse (T) directions and two EBW specimens are presented in Table 6, along with the corresponding average and standard deviation (SD) for replicate tests. The tensile engineering stress-strain curves for the room temperature tests of the various specimens are shown in Figure 9. A small step increase seen in some of the specimen curves well after the yield point is caused by increased crosshead speed (4x). ASTM E8 test method allows for a displacement rate increase to shorten the test time for specimens that exhibit high ductility. At least one specimen of each type was tested to failure at a constant displacement rate of $1.0 \mathrm{~mm} / \mathrm{min}$. The resulting ultimate tensile strength (UTS) increased for (L1 and L2) due the material's strain-rate dependence because the displacement rate was increased from 1 to $4 \mathrm{~mm} / \mathrm{min}$ after the yield point. A strain hardening behavior is observed for the $\mathrm{L}$ specimens, but is not measurable on the $\mathrm{T}$ specimens.

The tensile properties and mechanical response for the $\mathrm{T}$ direction are notably different from the $\mathrm{L}$ or rolling direction. The results in yield strength, reduction of area, and elasticity in the $\mathrm{T}$ direction are higher than in $\mathrm{L}$, while 
the ductility and strain hardening in the T direction is slightly lower than for the L orientation (Table 6). The photomacrographs displayed in Figure 10a and 10b show a moderately ductile fracture for both $\mathrm{L}$ and $\mathrm{T}$ samples. The ZR4-L1 specimen shows more of a ductile shear fracture, with a fracture line positioned at an approximate 30degree angle relative to the tension axis. The shear lips are parallel and just slightly discernable. They are slightly tilted at a 45-degree angle relative to the applied axial tensile stress, where the resolved shear stress reached its maximum along the most favorable slip systems. The ZR4-T1 specimen shows more of a cup-and-cone ductile fracture shape, where the shear lips are perpendicular to each other and show a 45-degree angle at the resolved shear stress direction relative to the applied tensile stress.

Table 6. Room temperature tensile properties of $\mathrm{Zr}-4$ sheet in $\mathrm{L}$ and $\mathrm{T}$ directions and $\mathrm{EBW}$ transverse specimens (rolling and weldment direction are parallel).

\begin{tabular}{lccccc}
\hline & Elastic Portion & \multicolumn{2}{c}{ Tensile Properties } & & \\
\multicolumn{1}{r}{ Specimen } & Line Slope, GPa & Offset Yield & UTS, & & Ductility, \\
Strength, MPa & MPa & RA, \% & \% \\
\hline ZR4-L1 & 78 & 500 & 640 & 45 & 22 \\
ZR4-L2 & 89 & 495 & 640 & 47 & 21 \\
ZR4-L3 & 93 & 494 & 620 & 44 & 21 \\
\hline Average & $\mathbf{8 6}$ & $\mathbf{4 9 6}$ & $\mathbf{6 3 3}$ & $\mathbf{4 5}$ & $\mathbf{2 0 . 9}$ \\
SD & 8 & 3 & 12 & 1.2 & 0.6 \\
\hline ZR4-T1 & 87 & 561 & 594 & 58 & 20 \\
ZR4-T2 & 85 & 563 & 614 & 56 & 19 \\
ZR4-T3 & 95 & 569 & 612 & 58 & 20 \\
\hline Average & $\mathbf{8 9}$ & $\mathbf{5 6 5}$ & $\mathbf{6 0 7}$ & $\mathbf{5 7}$ & $\mathbf{1 9 . 5}$ \\
SD & 5 & 4 & 11 & 0.9 & 0.5 \\
\hline \hline ZR4-EBW-W1 & 97 & 544 & 592 & 52 & 18 \\
ZR4-EBW-W2 & 95 & 537 & 608 & 58 & 20 \\
\hline Average & $\mathbf{9 6}$ & $\mathbf{5 4 1}$ & $\mathbf{6 0 0}$ & $\mathbf{5 5}$ & $\mathbf{1 9}$ \\
\hline
\end{tabular}




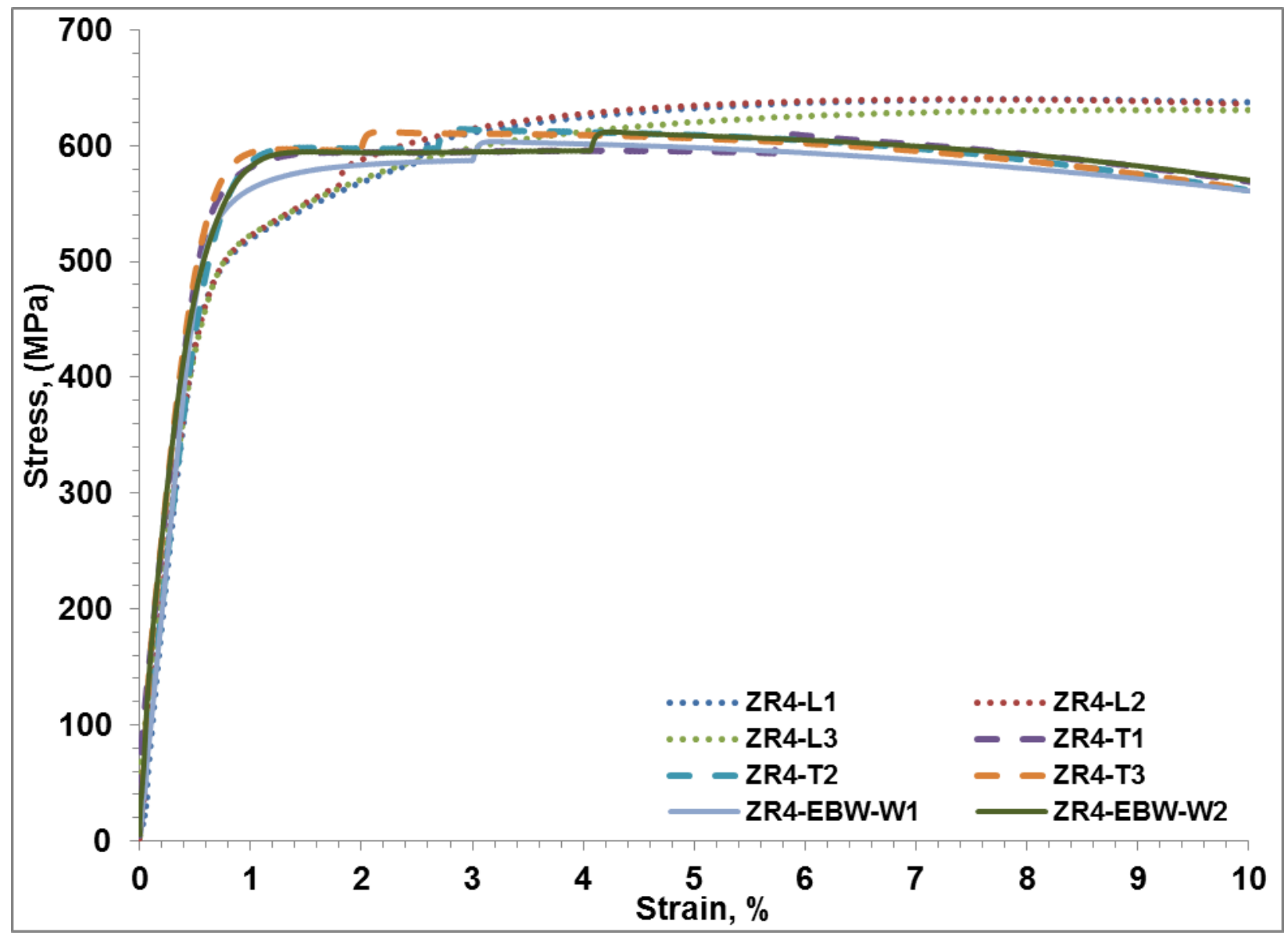

Figure 9. Zr-4 sheet specimen stress-strain curves.

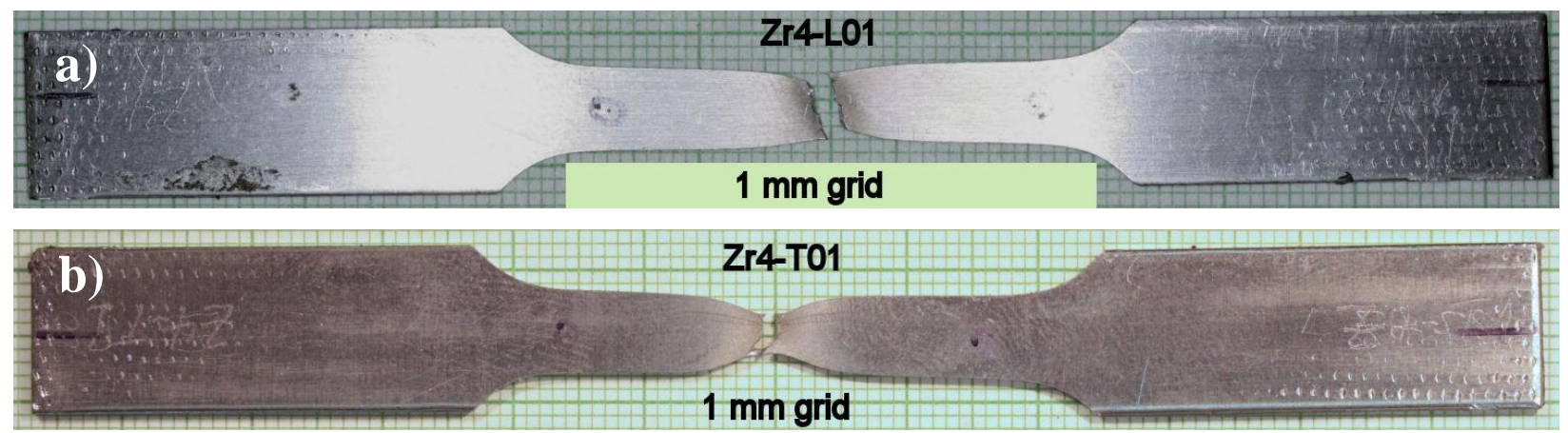

Figure 10. Zr-4 sheet subsize tensile test specimens after fracture under tension: (a) ZR4-L1 specimen loading axis parallel to sheet rolling (L) direction and (b) ZR4-T1.

The lower yield strength and higher ductility in the $\mathrm{L}$ when compared to the $\mathrm{T}$ direction is partially the result of grain alignment parallel to the rolling direction, which improves the ease of dislocation movement along preferential slip directions in the crystals. The engineering properties observed for $\mathrm{Zr}-4$ are highly crystallographic texture- 
dependent and influenced by sheet forming process and subsequent heat treatment (if applied). This anisotropic behavior is expected for $\mathrm{Zr}$ and $\mathrm{Zr}$-rich alloys as a result of the hexagonal, closed, packed crystal structure. During cold working, the HCP crystals deform on preferred orientations in the crystal by both slip and twinning. The anisotropic properties of a Zircaloy strip results in significantly higher yield strength values in the T direction because cold-rolled Zircaloy strip has a strong normal texture, where most of the basal poles of the hexagonal crystals are orientated about 35 degrees to the T plane of the strip. Table 7 provides data extracted from ASTM B352 and ATI Wah Chang Technical Data Sheet (2003) to show a comparison of room temperature tensile properties in the $\mathrm{T}$ and $\mathrm{L}$ for $\mathrm{Zr}-4$. This behavior has been also studied in $\mathrm{Zr}$ and $\mathrm{Zr}-2.5 \mathrm{Nb}$ alloys. Salinas-Rodríguez and Jonas (1992) observed the high temperature (i.e., 923 to 1123K) texture evolution under uniaxial tension and compression in $\mathrm{Zr}$ and $\mathrm{Zr}-2.5 \mathrm{Nb}$. Christodoulou et al. (2000) studied the anisotropy of yielding in $\mathrm{Zr}-2.5 \mathrm{Nb}$ pressure tubes that were used in the Canada deuterium uranium nuclear reactors. Kaschne et al. (2000) found that the compressive-yield responses of high and low-purity $\mathrm{Zr}$ depend on the loading orientation relative to the c-axis of the hexagonal closed packed cell. Carr et al. (2007) studied the variations in residual lattice strains parallel and perpendicular to the applied stress with neutron diffraction measurements on a variety of crystallographic reflections.

Table 7. Tensile properties of annealed $\mathrm{Zr}-4$ at room temperature.

\begin{tabular}{cccccc}
\hline & \multicolumn{5}{c}{ Mechanical Properties } \\
\cline { 3 - 5 } Grade & Specimen & $\begin{array}{c}\text { Yield Strength } \\
(\mathbf{0 . 2 \%} \text { offset), Mpa }\end{array}$ & $\begin{array}{c}\text { UTS, } \\
\text { MPa }\end{array}$ & $\begin{array}{c}\text { Elongation in 50mm, } \\
\text { min. \% }\end{array}$ & Reference \\
\hline Zr-4 (R60804) & L & 240 & 400 & 25 & ASTM B352 \\
& $\mathrm{T}$ & 300 & 385 & 25 & \\
Zr-4 (R60804) & $\mathrm{L}$ & 381 & 541 & 28 & ATI Wah Chang \\
& $\mathrm{T}$ & 468 & 515 & 29 & \\
\hline
\end{tabular}




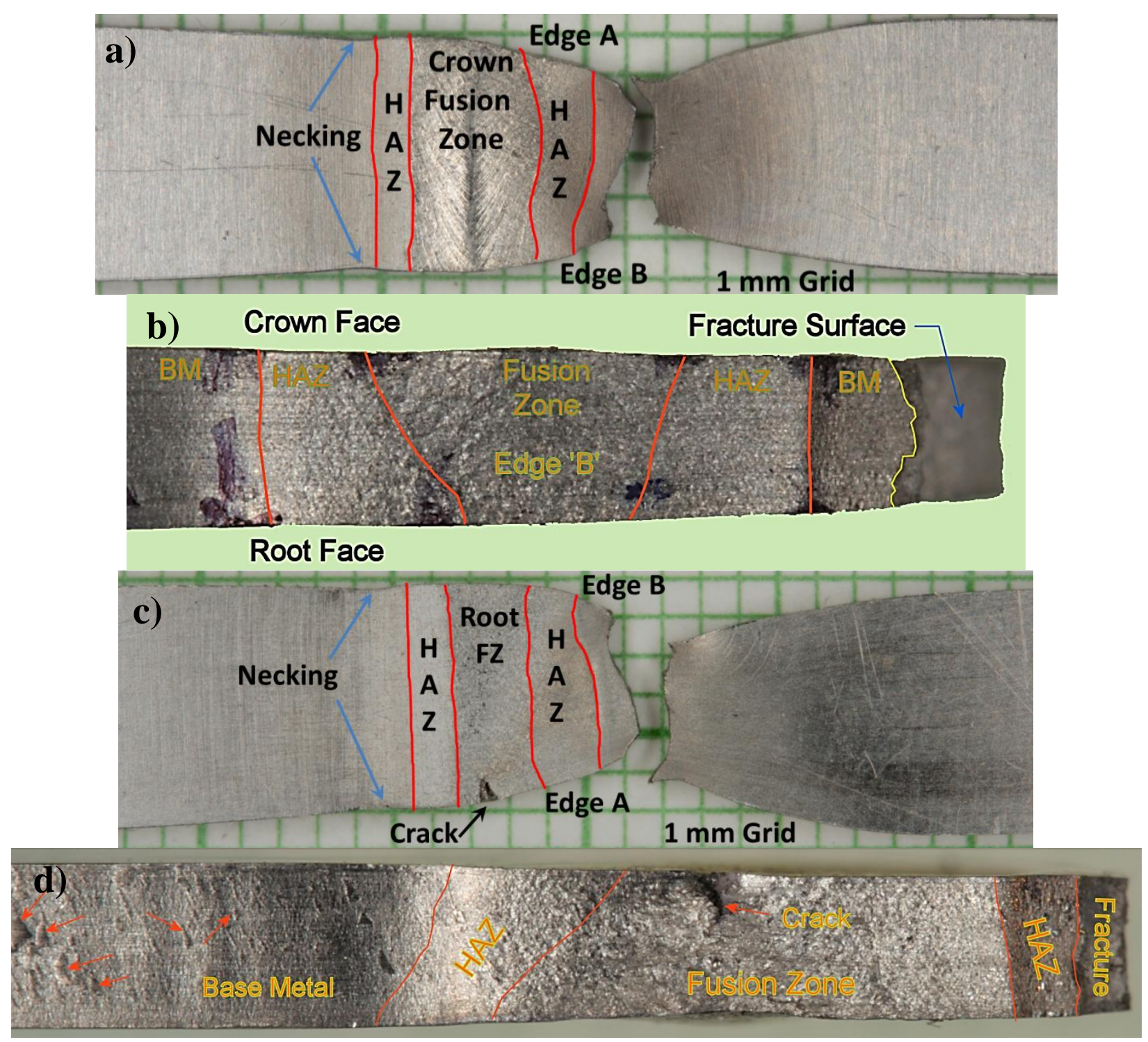

Figure 11. Welded Zr-4 specimen (ZR4-EBW-W1) after fracture under tension: (a) crown face view, (c) root face view, and (b) and (d) are both edges of a fractured sample.

A set of macrographs of the ZR4-EBW-W1 post-tensile specimen are shown in Figure 11. The EBW fractured specimen more closely resembles the $\mathrm{T}$ specimen, but there are some similarities orientation-wise that relate to the $\mathrm{L}$ specimen's fracture pattern. The fracture has a z-shape and it denotes a crack that grew along very particular crystalline directions and at the final stage encountered a boundary that modified its trajectory at a 60-degree angle relative to the initial crack growth direction. The top view (i.e., weld crown face) of the fracture specimen is shown in Figure 11a, with the weld region delineated. The fracture location and secondary partial necking site are observed. The sample failure site and secondary partial necking took place outside the weld area and apparently not within the 
HAZ. Besides some partial area reinforcement from the rather smooth weld crown, there is some indication of the relative higher strength of the weld area in comparison to the surrounding base metal. Figure 11b shows a side view of the fractured specimen, with weld region zones and fracture site delineated. Figure 11c provides a bottom view (i.e., weld root face) of the ZR4-EBW-W1 fractured tensile sample, showing a crack that initiated at the weld root side of the fusion zone. This crack might have originated at the location where the sheet pieces were originally sectioned and subsequently welded. However, it appears that the critical stress for crack propagation was not reached and the crack did not grow any further at this location, because the sample failed at the base metal. In Figure $11 \mathrm{~d}$, the crack at the weld root fusion zone is observed from a different angle (i.e., edge view). The crack grew perpendicular to the load axis about one-third into the through-thickness of the specimen during tensile testing. Additionally, in Figure 11d red arrows are used to point out some dimples formed during plastic deformation at the secondary necking site. There is no indication of cold cracking at the HAZ because the fracture site and necking are located just outside the HAZ into the base metal site.

The tensile properties obtained from specimens with the $\mathrm{T}$ welds are equivalent (within experimental accuracy) to the $\mathrm{T}$ base metal test results. Besides the seal or weld crown leveling pass performed during the EBW process, the weld crown was not removed, leveled, or made uniform by machining prior to testing. The weld region has the appearance of a very slight elevated crown in the metallographic mount images. Some minimal area reinforcement may be very slightly reducing the applied stress in the weldment region. Tests of these specimens exhibited specimen yielding and subsequent strain localization entirely within the base metal surrounding the weld HAZ, but within the extensometer gauge length. As such, the measured properties of yield strength and UTS should match T base metal test results within an accepted specimen-to-specimen variability for tensile test specimens of this size and geometry. Geometric constraint arising from the proximity of the possibly higher-strength weld metal region may have a slight effect on the measured ductility and area reduction, but test results suggest that any difference is statistically irrelevant.

\subsection{Nanohardness and Microhardness Testing}

The nanohardness values obtained for as-received $\mathrm{Zr}-4$ sheet samples with loads ranging from 50 to $500 \mathrm{mN}$ and their corresponding SD are presented in Table 8. A load of $500 \mathrm{mN}$ was used in order to reduce the indentation- 
size-effect by reducing the influence of individual grains to obtain measurements associated to the bulk material's hardness (see Subsection 3.4 for grain-indentation size ratio values).

Table 8. Hardness (with standard deviation) as a function of indent force for a plain $\mathrm{Zr}-4$ sheet.

\begin{tabular}{ccc}
\hline $\mathbf{P}, \mathbf{m N}$ & $\mathbf{n H}, \mathbf{G P a}$ & $\mathbf{S D}, \mathbf{G P a}$ \\
\hline 500 & 2.46 & 0.23 \\
300 & 2.42 & 0.14 \\
200 & 2.36 & 0.19 \\
100 & 2.66 & 0.39 \\
50 & 2.54 & 1.11 \\
\hline
\end{tabular}

The photomicrograph of the etched "met specimen" is shown in Figure 12. The weld cross section shows a dark equilateral triangle-like shape surrounded by the base metal. The weld root side is toward the top and the crown side is toward the bottom. The EBW parameters used in this study produced a weld with a 0.6:1 depth-to-width aspect ratio, which gives some indication of the weld robustness. In this regard, Zirker (2016) stated that experimental work has shown that an adequate weld depth-to-width aspect ratio for welding in general has been found to be within 0.7 to 1, with the optimum being closer to 0.7. Elmer et al. (1990) explain that the ideal value predicted by the Rosenthal's point-source model is 1:2 weld depth-to-width aspect radio for high-power density welding techniques as electron beam welding. Furthermore, the four black diamond shapes visible to either side of the weld and HAZ region are Vickers indents used as coordinate fiducial marks so the weld boundaries could be located after subsequent re-polishing of the surface. The weld metal (fusion) region is clearly delineated by the etchant. More equiaxed, but relatively larger, grains are seen close to the fusion boundary that represents the HAZ. The uniform smaller grains of the base metal are seen toward the left and right (generally lighter color). The nominal direction and progression of fusion region solidification are indicated by the red arrows in Figure 12. However, this image only shows a Y-Z plane cross section of the weld and the feather-like columnar grains also solidify at an angle with respect to the $\mathrm{Y}-\mathrm{Z}$ plane into the X-direction. Figure 13 shows the weld molten pool with welding direction and various isotherms calculated using Rosenthal's 3D heat flow equation. As the heat source (i.e., electron beam) travels along the seam in the welding direction, the molten metal re-solidifies behind the electron beam. During cooling the first solid embryos will nucleate at the solid/liquid interface (weld/HAZ boundary) after slight under cooling below the solidus temperature. Afterwards grains will grow into the liquid between the liquidus ( $\mathrm{T}=$ $\left.1850^{\circ} \mathrm{C}\right)$ and solidus $\left(\mathrm{T}=1700^{\circ} \mathrm{C}\right)$ isotherms, in a direction opposite to the heat flow toward the weld crown in a columnar or feather like pattern as depicted by the red and blue arrows in Figure 12 and 13, respectively. The fusion 
boundary is a demarcation of maximum temperature exceeding the material solidus point. Heat flow is nominally outward from the fusion region during cooling and solidification; however, rates vary depending on the proximity of the surface boundaries. The HAZ in the root region achieves higher temperatures for longer times due to the proximity of the back surface where radiant heat loss is lower than conducted heat loss within the base metal. This time-temperature difference correlates to larger grains (more grain growth) in that region. The resultant microstructure variation due to differing time-temperature histories can create local changes in the mechanical properties.

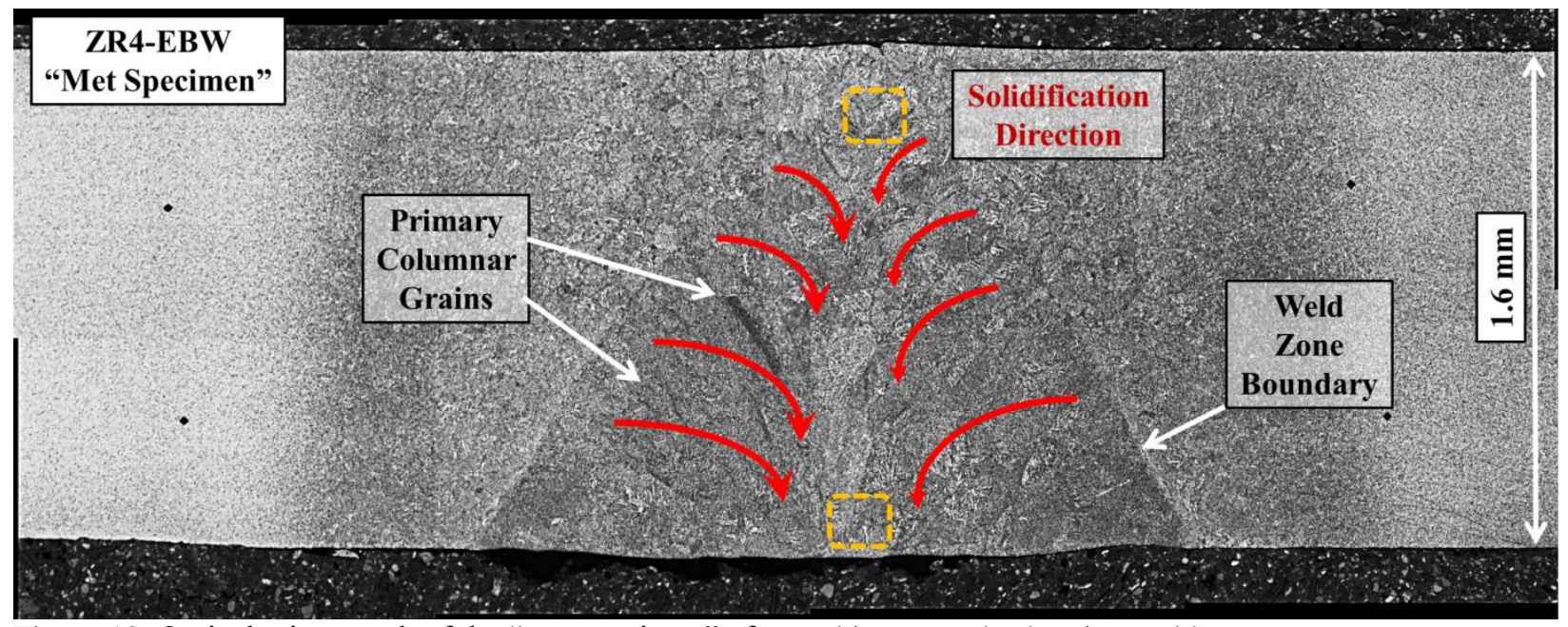

Figure 12. Optical micrograph of the "met specimen" after etching; sample showing weld.

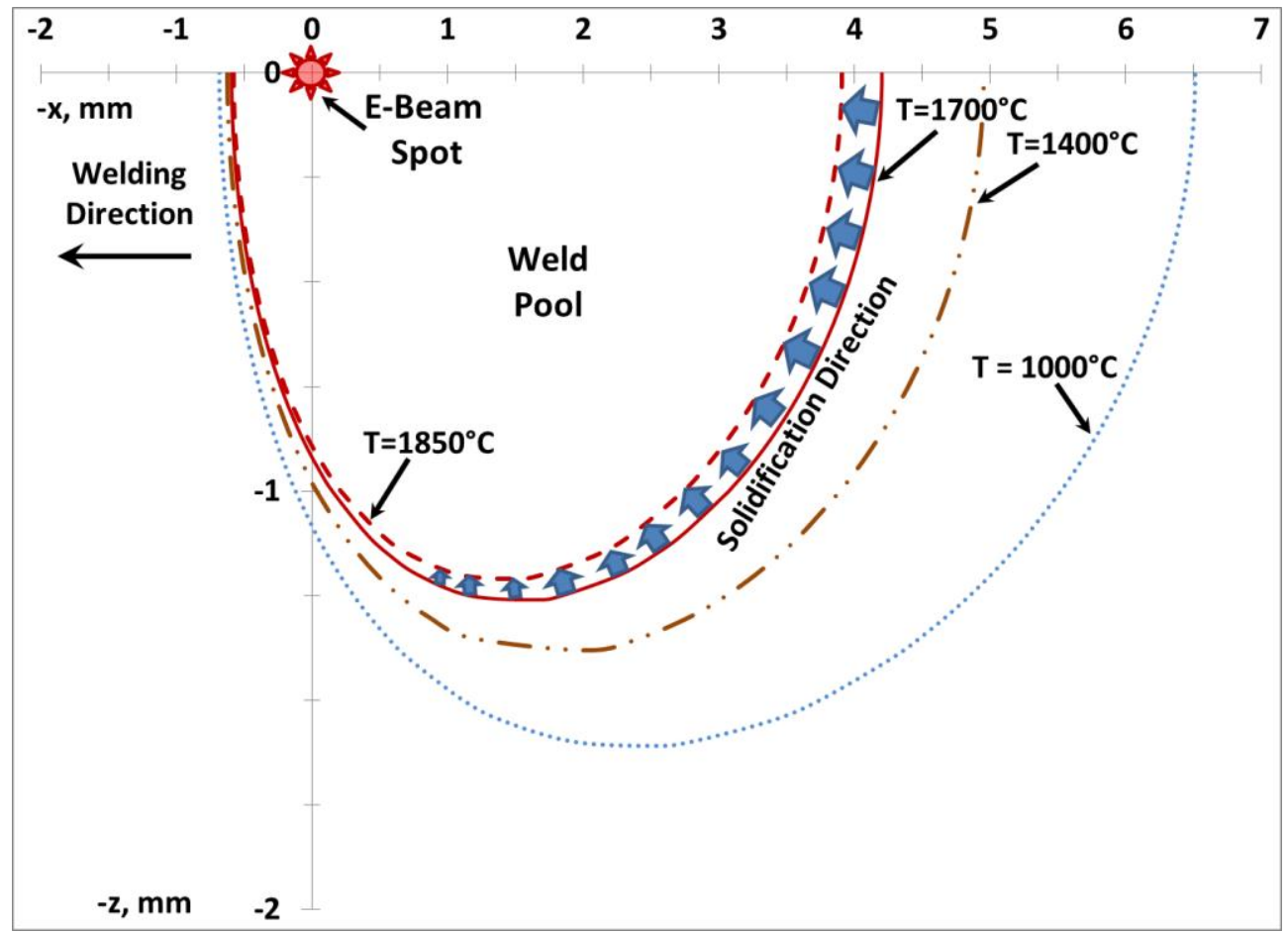


Figure 13. Weld pool boundary in $\mathrm{X}-\mathrm{Z}$ plane at $\mathrm{y}=0$ calculated Rosenthal's three-dimensional heat flow equation.

Table 9 shows an average value of the nanohardness per zone and the SD and standard error (SE) calculations. The areas of interest (i.e., weld, HAZ, and base metal) have been delineated based on visual inspection, hardness testing, and electron and optical microscopic analysis. The HAZ range used for tabulation was approximated to be around $500 \mu \mathrm{m}$. Based on the values in Table 9, the weld is about $0.8 \%$ harder than the base metal and the HAZ hardness is about $3 \%$ higher than the base metal. These values fall within the standard deviation and are statistically non-differentiable, inferring comparable properties for the base metal and weld region.

Table 9. Weld region average nanohardness values per zone, plus corresponding SD and SE of the mean.

\begin{tabular}{clccc}
\hline Sample ID & \multicolumn{1}{c}{ Zone } & nH, GPa & SD, GPa & SE, GPa \\
\hline Zr-4 Met Specimen & Weld & 2.482 & 0.257 & 0.010 \\
& HAZ & 2.529 & 0.263 & 0.014 \\
& Base Metal & 2.462 & 0.284 & 0.013 \\
\hline
\end{tabular}

A series of overlaying plots consisting of nanohardness and Vickers microhardness scans from the weld centerline outward into the base metal are presented in Figure 14a and 14b, respectively. Two dashed parallel vertical lines demark the limits of the weld area. The weld boundary range increases downward from the weld root toward the weld crown (Figure 12). There is a local hardness maximum around the weld centerline and then hardness decreases toward the weld boundary, again spikes up at the HAZ, and again decreases and slightly levels out into the base metal. This pattern is more evident in the Vickers plot, because the larger indentation size and depth measures the hardness of a greater number of primary grain islands and is less prone to interference by a grain region where smaller microstructural features may be preferentially aligned. Table 10 shows the grain-indent size ratio comparison for both nanohardness and microhardness indents relative to the measurement zone. The Berkovich nano-indenter intersects approximately 3-9 grains and the Vickers micro-indenter covers about 7-18 grains depending on the zone where the measurement is performed. 


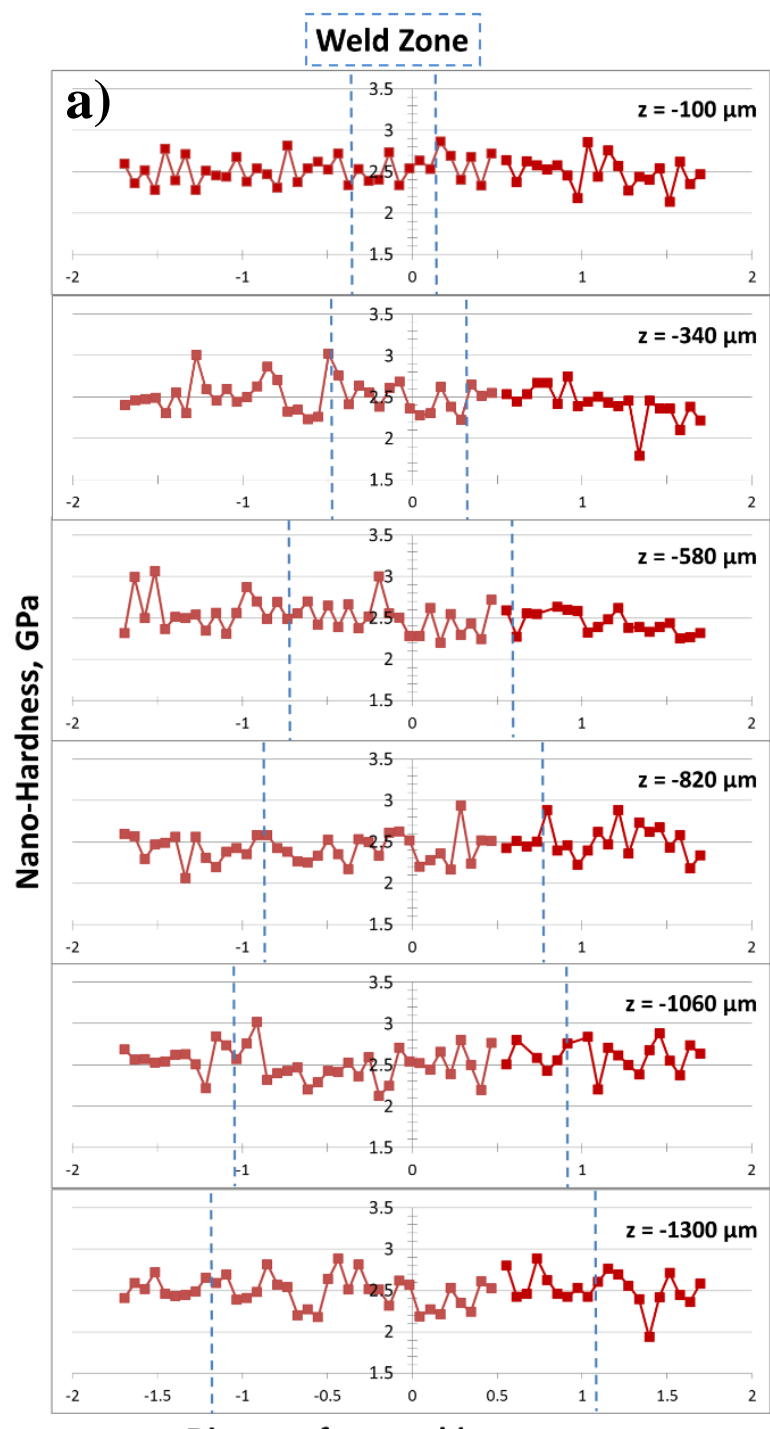

Distance from weld center, $\mathrm{mm}$

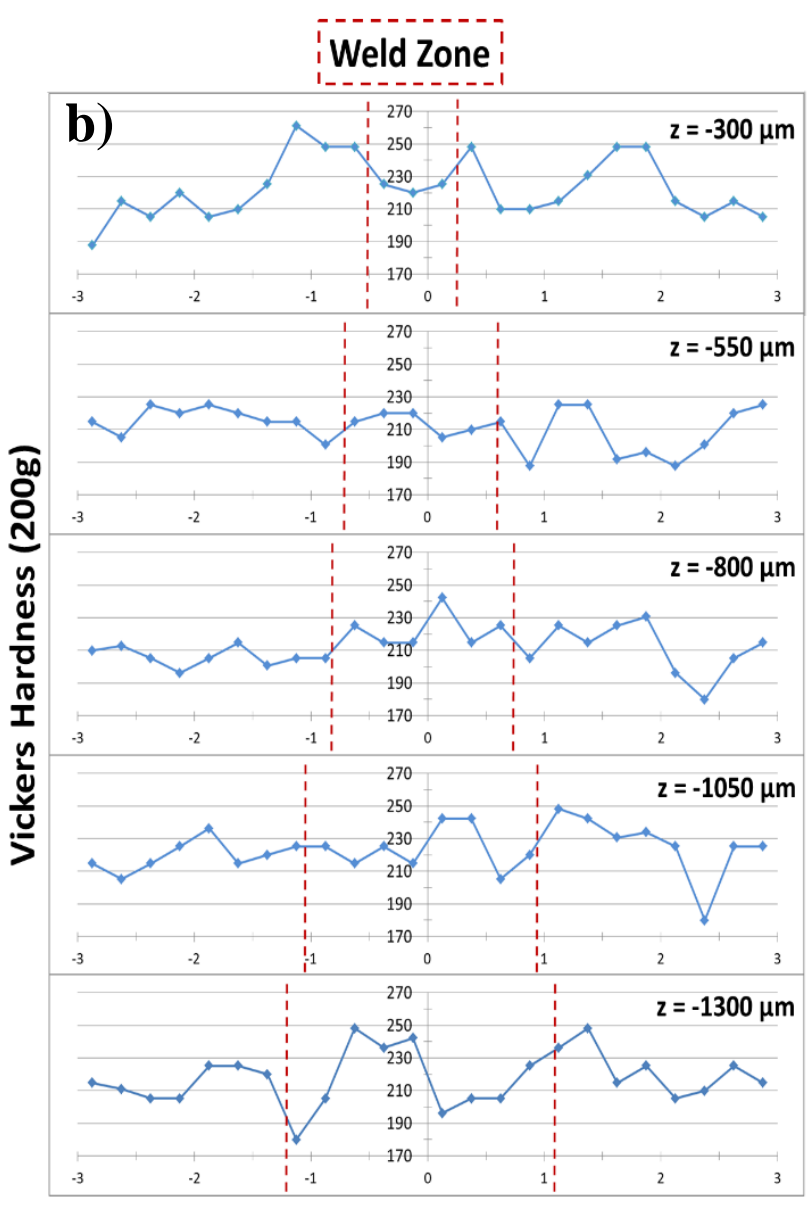

Distance from weld center, $\mathrm{mm}$

Figure 14. Hardness profile of the EBW Zr-4 metallurgical sample around the weld centerline: (a) nanohardness, and (b) Vickers microhardness scans. Z-values indicate the distance from the root-side surface to hardness scan line.

A slightly higher hardness at the HAZ (i.e., thermally promoted grain growth) is caused by localized stresses produced by grain size (Table 10), microstructure morphology (see Subsection 3.4), grain orientation mismatch at the transition region between the weld (i.e., newly formed grains) and base metal (i.e., rolled sheet microstructure). Local grain boundary incoherence between the weld and base metal will obstruct the dislocation movement during deformation, causing a pile-up at the grain boundaries that introduces stress concentration ahead of the dislocation slip planes and generating new dislocations in adjacent planes. Furthermore, there is correlation between higher local hardness around the weld centerline and the solidification direction (see Figures 14a and 12). The temperature gradient produced in the axial and radial direction during EBW caused primary columnar grain nucleation at the 
weld/HAZ boundary and growth inward toward the weld crown, pushing the weld solidification front into the molten metal (Figures 12 and 13). The weld axis shows a correlation between higher hardness and larger grains. Several grains were randomly selected and measured at the weld crown (Figure 15a) and weld root (Figure 15b) in two areas enclosed in dashed squares in Figure 12, respectively. The hardness values and grain size vary along the weld axis, showing relatively larger grains (i.e., $43 \mu \mathrm{m}$ grain size length) and higher hardness at weld crown (248 HV); toward the weld root the grain size decreases (i.e., $36 \mu \mathrm{m}$ grain size length) and hardness gradually goes down (220 HV).

Table 10. Grain size per zone measurement and grain-to-indent size relationship for nano- and micro hardness.

\begin{tabular}{|c|c|c|c|c|c|c|c|c|c|c|c|c|}
\hline \multirow[b]{2}{*}{ Zone } & \multicolumn{2}{|c|}{$\begin{array}{c}\text { Grain Size } \\
\text { Average, } \mu \mathrm{m}\end{array}$} & \multicolumn{2}{|c|}{$\begin{array}{c}\text { Standard } \\
\text { Deviation, } \\
\mu \mathrm{m}\end{array}$} & \multirow[t]{2}{*}{$\begin{array}{c}\text { nH } \\
\text { Indent } \\
\text { size, } \\
\mu \mathrm{m}\end{array}$} & \multirow{2}{*}{$\begin{array}{l}\text { SD, } \\
\mu \mathrm{m}\end{array}$} & \multicolumn{2}{|c|}{$\begin{array}{c}\text { Grain/nH } \\
\text { Indent } \\
\text { Size } \\
\text { Ratio }\end{array}$} & \multirow{2}{*}{$\begin{array}{c}\mu \mathrm{H} \\
\text { Indent } \\
\text { size, } \\
\mu \mathrm{m} \\
\end{array}$} & \multirow{2}{*}{$\begin{array}{l}\text { SD, } \\
\mu \mathrm{m}\end{array}$} & \multicolumn{2}{|c|}{$\begin{array}{c}\text { Grain/ } / \mu \mathbf{H} \\
\text { Indent } \\
\text { Size } \\
\text { Ratio }\end{array}$} \\
\hline & Length & Width & $\mathbf{L}$ & W & & & $\mathbf{L}$ & W & & & $\mathbf{L}$ & W \\
\hline $\begin{array}{l}\text { Weld } \\
\text { Crown }\end{array}$ & 42.9 & 2.9 & 6.4 & 1.2 & & & 2.1 & 0.1 & & & 1.0 & 0.1 \\
\hline $\begin{array}{l}\text { Weld } \\
\text { Root }\end{array}$ & 35.8 & 2.4 & 5.5 & 1.1 & 20.6 & 0.2 & 1.7 & 0.1 & 42.8 & 1.6 & 0.8 & 0.1 \\
\hline HAZ & 16.0 & 2.5 & 2.7 & 0.8 & & & 0.8 & 0.1 & & & 0.4 & 0.1 \\
\hline $\begin{array}{l}\text { Base } \\
\text { Metal }\end{array}$ & 6.2 & 6.2 & 1.2 & 1.2 & & & 0.3 & 0.3 & & & 0.1 & 0.1 \\
\hline
\end{tabular}

Table 10 presents detailed grain size measurements performed at the weld region. The smaller equiaxed grains (i.e., base metal) were measured along two perpendicular directions and the size was averaged. Usually, their dimensions were either the same or very similar, providing evidence of their regular shape. The needle (i.e., HAZ) and platelet (i.e., weld zone) grains were measured along their length and width. The weld zone measurements were separated in either weld crown or weld root to evaluate variations in grain size along the weld axis. Approximately 100 grains were measured to quantify microstructural differences between weld, HAZ, and base metal. Length-wise the weld crown has relatively larger grains (i.e., about 16\%) than the weld root. The HAZ has grains with a length almost three times the size of the base metal and about half the size of the weld grains. The weld and HAZ have elongated grains with a similar width size, and the base metal has equiaxed grains with a size just over twice the width of the elongated grains at the weld and HAZ. 


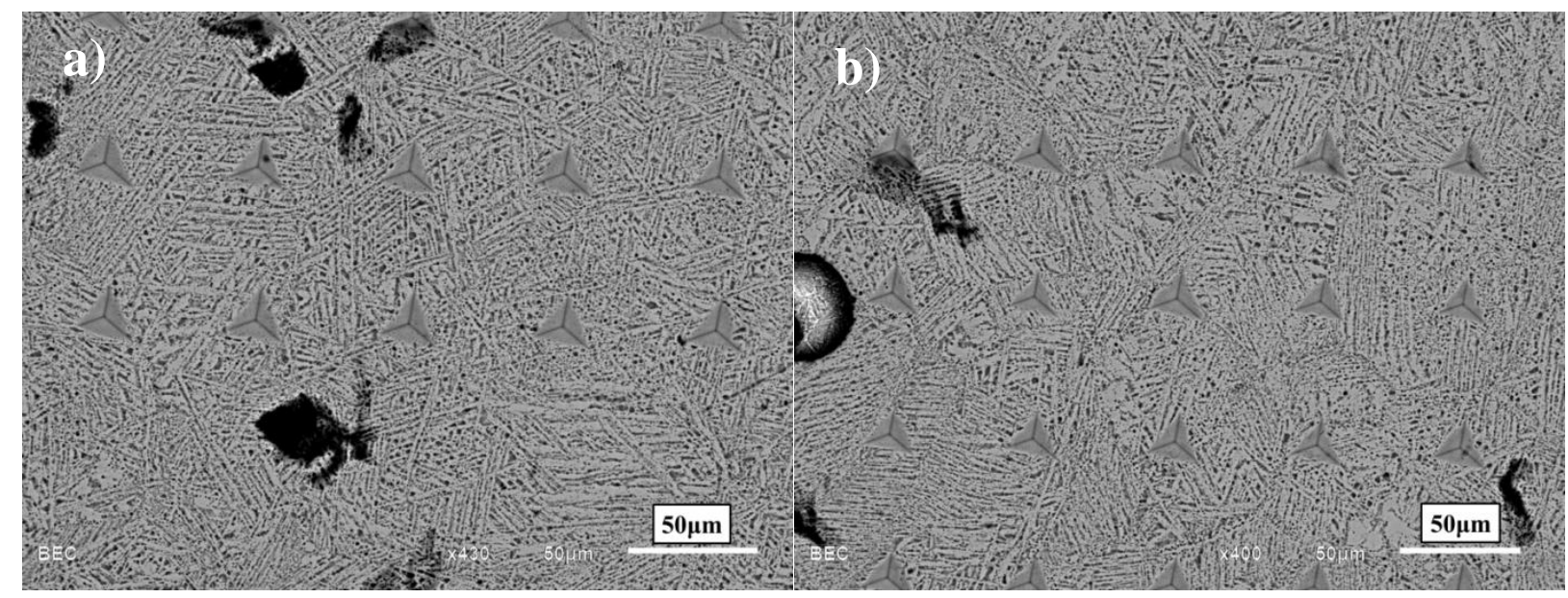

Figure 15. SEM micrographs used for grain size measurements along the weld axis at (a) weld crown and (b) weld root.

\subsection{Microstructure Morphological Analysis}

A series of secondary electron micrographs are presented to analyze the microstructural differences between weld, HAZ, and base metal zone (see Figures 16 through 18). This section complements the tensile and hardness analysis to understand the influence of EBW on microstructure and its effect on mechanical properties.

During solidification at the weld zone $(\mathrm{L} \rightarrow \beta \mathrm{Zr})$, initially the formation of primary $\beta \mathrm{Zr}$ long columnar grains in a feather-like structure took place (see Figures 8 and 12). Upon further cooling, the body-centered cubic Zr phase rapidly (comparable to a martensitic transformation in steels) underwent a eutectoid reaction $(\beta \mathrm{Zr} \rightarrow \alpha \mathrm{Zr}+\mathrm{ZrX})$ and formed a lamellar-like structure composed of large platelets of the hexagonal, closed, packed Zr phase (light gray) with a minor, inter-platelet, alloying-element-rich phase (dark) primarily composed of intermetallic compounds (probably $\mathrm{Zr}_{3} \mathrm{Fe}$ and $\mathrm{ZrCr}_{2}$ because chromium and iron have negligible solubility in $\alpha \mathrm{Zr}$ when compared to $\mathrm{Sn}$ ) in Widmanstätten structure pattern (typically formed in iron-nickel meteorites during slow cooling). The large platelets display their peculiar 60 to 90-degree angle at grain intersections, depending on their orientation relative to the polished surface (see Figure 16). The HAZ has an acicular alpha-zirconium microstructure that formed from the original base metal structure. The HAZ has larger and morphologically different grains (see Figure 17) than the base metal due to the thermally induced grain growth caused by heat diffusing away from molten metal (weld junction) into the surrounding solid during EBW. The base metal shows a finer and more equiaxed-grain alpha structure (see Figure 18) formed during the work hardening (rolling) and subsequent annealing (recrystallization) process. The 
needle-like grains at the HAZ can be explained as a morphological intermediate transformation step between the base metal recrystallized grains and the solidified weld microstructure.

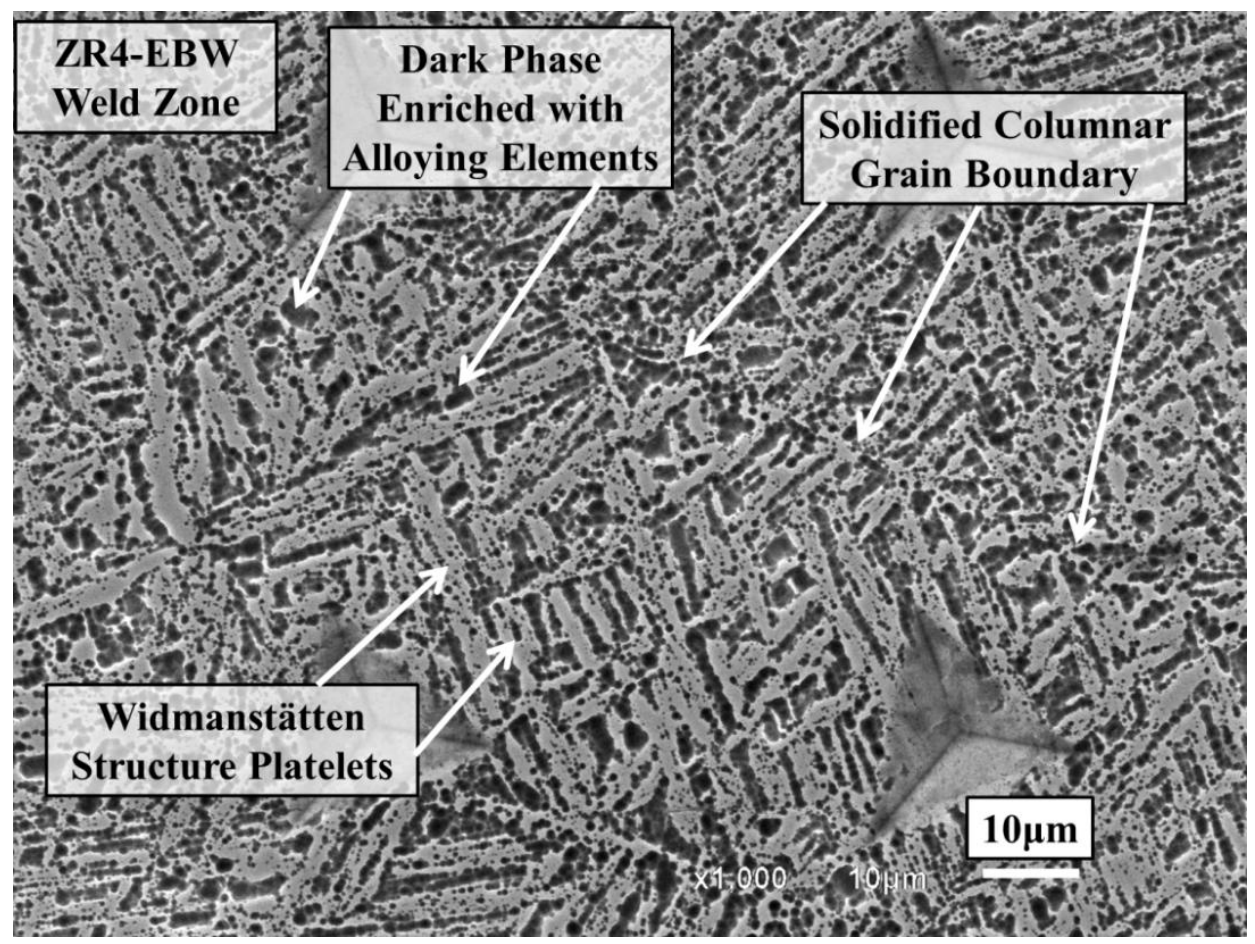

Figure 16. Electron micrograph of weld zone showing Widmanstätten structure.

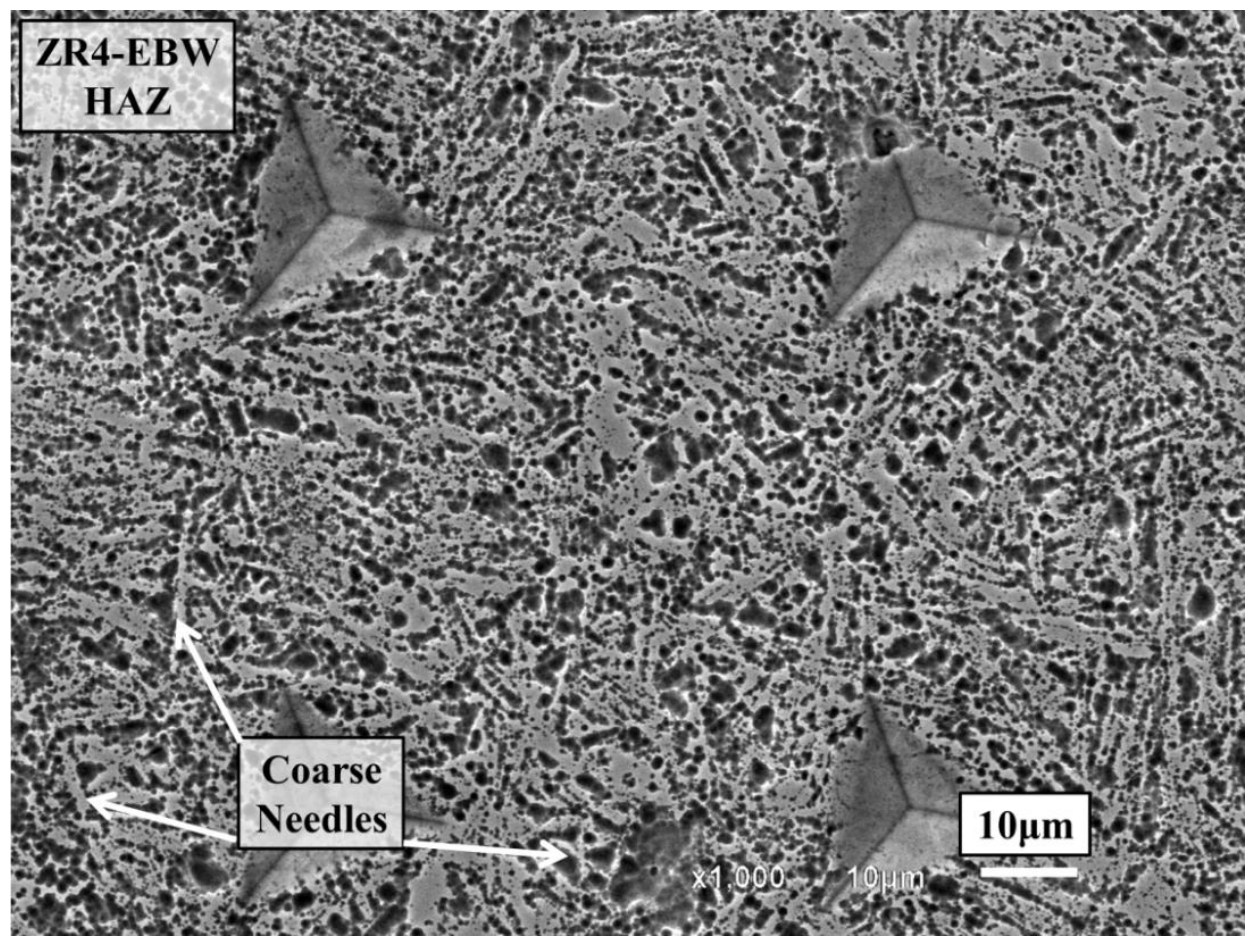

Figure 17. Weld-BM transition (HAZ), electron micrograph. 


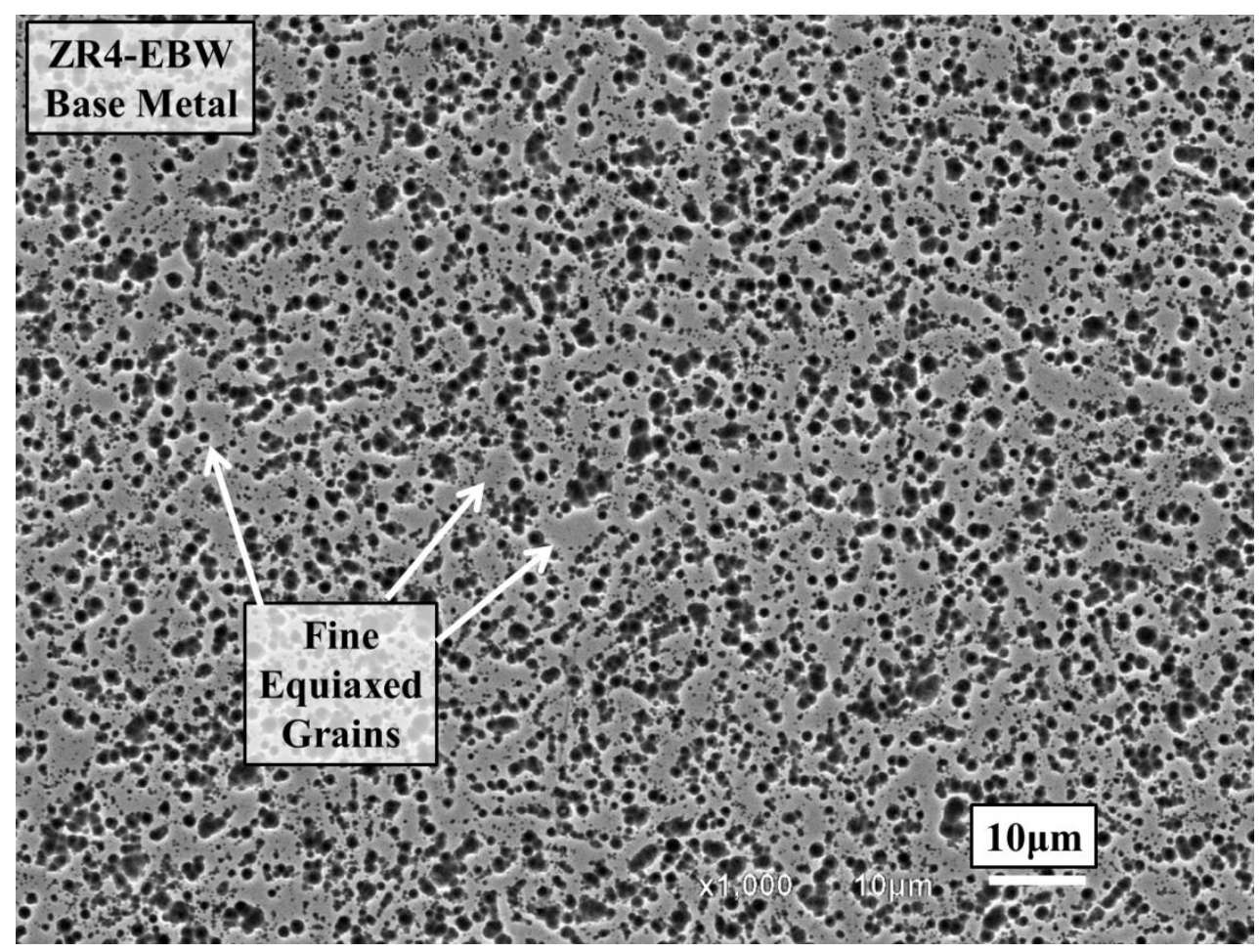

Figure 18. SEM micrograph showing base metal finer acicular structure.

\section{CONCLUSIONS}

- $\mathrm{Zr}$-4 sheet $(1.6 \mathrm{~mm})$ was successfully welded using an EBW three-pass process. The sheet was first tack welded $(10.5 \mathrm{~J} / \mathrm{mm})$ and then seam welded $(36.7 \mathrm{~J} / \mathrm{mm})$ with a final seal pass $(15.7 \mathrm{~J} / \mathrm{mm})$.

- Calculation of weld and the HAZ boundary using Rosenthal's welding analytical equation for threedimensional heat flow in a semi-infinite workpiece correlates well to the experimental measurements and provides more evidence for weld solidification in the front direction and primary columnar grain formation in a feather-like fashion.

- The EBW parameters utilized to weld the $\mathrm{Zr}-4$ sheet (1.6-mm thick) presented in this study have produced a welded material that has mechanical properties that closely resemble the as-received $\mathrm{Zr}-4$ sheet properties.

- The Zr-4 plain sheet displays anisotropy. The tensile properties measured for transverse specimens show a relatively higher stiffness than the longitudinal specimens (i.e., rolling direction): higher yield strength at 
about $14 \%$, reduction of area at about $27 \%$, lower ductility at about $7 \%$, and ultimate tensile strength at about $4 \%$.

- The EBW tensile specimen failed at the base metal just outside the HAZ and also showed some necking at the opposite side of the weld outside the HAZ. This is an indication of weld robustness and mechanical strength.

- The weld has similar hardness as the base metal (weld is about $0.8 \%$ harder). Hardness slightly increases at the weld-base metal transition (i.e., the HAZ) and finally levels out at the base metal. The HAZ has a higher hardness than the base metal (i.e., about 3\%) and weld zone (i.e., about 2\%). Overall hardness differences are statistically insignificant.

- $\quad$ SEM examination shows a distinct microstructure morphology and grain size across the weld zone, HAZ, and into the base metal. The grains are the largest at the weld $(39.5 \mu \mathrm{m})$ and become smaller and more regular into the base metal $(6 \mu \mathrm{m})$. The weld shows predominantly large $\alpha \mathrm{Zr}$ platelets in a Widmanstätten pattern. The HAZ is composed of an acicular $\alpha \mathrm{Zr}$ grain structure. The base metal shows an equiaxed fine grained $\alpha \mathrm{Zr}$ structure.

\section{ACKNOWLEDGEMENTS}

This work has been performed under the auspices of and supported by the U.S. Department of Energy National Nuclear Security Administration. Jatu Burns, Allyssa Bateman, Bryan Forsmann, and Todd Morris are acknowledged for nanohardness, electron microscopy, optical microscopy, and sample preparation.

\section{REFERENCES}

ATI Wah Chang, 2003. Reactor Grade Zirconium Alloys for Waste Disposal. Technical Data Sheet, ZirAly-019, Allegheny Technologies Incorporated, www.atimetals.com, 1-4.

Carr, D. G., Holden, T. M., Ripley, M. I., Brown, D., Vogel, S. C., 2007. Investigation on Grain-Scale Stresses and Modeling of Tensile Deformation in a Zircaloy-4 Weldment. Metallurgical and Materials Transactions A. 38A, 2410-2418. 
Christodoulou, N., Turner, P.A., Ho, E.T.C., Chow, C.K., Resta, L.M., 2000. Anisotropy of Yielding in a Zr-2.5Nb Pressure Tube Material. Metallurgical and Materials Transactions A. 31A, 409-420.

Comstock, R., Barbéris P., (Eds.) 2015. Zirconium in the Nuclear Industry, $17^{\text {th }}$ International Symposium, ASTM International, West Conshohocken, PA, ISBN: 978-0-8031-7529-7, ISSN: 1050-7558.

Elmer, J.W., Giedt, W.H., Eagar, T.W., 1990. The Transition from Shallow to Deep Penetration during Electron Beam Welding. Welding Journal, Welding Research Supplement, 167s-176s.

Kaschner, G.C., Gray, G.T. III, 2000. The Influence of Crystallographic Texture and Interstitial Impurities on the Mechanical Behavior of Zirconium. Metallurgical and Materials Transactions A. $31 \mathrm{~A}, 1997-2003$.

Krishnan, R., Asundi, M.K., 1981. Zirconium Alloys in Nuclear Technology. Proc. Indian Acad. Sci (Engg. Sci.). 4, 1, 41-56.

Lyons, P.B., 2010. Resumption of Transient Testing of Nuclear Fuels Project Approval of Critical Decision (CD) 0, Approve Mission Need. PBL-12-2-2010, December 3, 2010.

Mehrer, H., 2007. Diffusion in Solids: Fundamentals, Methods, Materials, Diffusion-Controlled Processes, Springer Berlin Heidelberg, http://dx.doi.org/10.1007/978-3-540-71488-0_8, 127-149, 297-312.

Milosavljevič, D., 1962. Electron Beam Welding of Zircaloy-2. Proceedings of Conference on the use of Zirconium Alloys in Nuclear Reactors. Mariánske Lázně, Czechoslovakia, October 1-3, 1962, 369390.

Parga, C.J., 2013. Very High Temperature Measurements: Applications to Nuclear Reactor Safety Tests. Thesis/Dissertation, IAEA-INIS, Pub. No. FRCEA-TH—6122, INIS. 46, 39, 4-25.

Rosenthal, D., 1941. Mathematical theory of heat distribution during welding and cutting. Welding Journal. 20, 220-234. 
Salinas-Rodríguez, A., Jonas, J.J., 1992. Evolution of Textures in Zirconium Alloys Deformed Uniaxially at Elevated Temperatures. Metallurgical Transactions A. 23A, 271-293.

Schultz, H., 1994. Electron Beam Welding, first ed. Woodhead Publishing Series in Welding and Other Joining Technologies, 28-38, 64-91.

Semenov, A.N., Plyshevskii M.I., Gordo, V.P., Rassoshkina, N.S., Melyukov, V.V., Korepanov, A.G., 2013. Optimization of the Heating Source in Electron Beam Welding of Zirconium Pipes. Welding International. 27, 4, 300-303.

Suzuki, H., Hashimoto, T., Matsuda, H., 1962. Electron-Beam Welding for Pure Zirconium and Zircaloy2 Alloy. (Original article written in Japanese), Yosetsu Gakkai Shi/Journal of the Japan Welding Society. 31, 1, 44-52.

Tomie, M., Abe, N., Hano, M., Shirabe, T., 1990. Electron Beam Welding of Zirconium Plate. Transactions of Japan Welding Research Institute of Osaka University, Ibaraki, Osaka. 567, Japan. $19,1,149-150$.

van Rooyen, I.J., Morrell, S.R., Jamison, R.K., Crawford, A.L., Hartman, III H.T., Luther, E.P., Wright, A.E., Kontogeogakos, D.C., Papadias, D.D., Connaway, H.M., Yesi-lyurt, G., 2014. Paper INL/CON14-33130. In: RERTR 2014 - 35th International meeting on Reduced Enrichment for Research and Test Reactors. IAEA Vienna International Center, Vienna, Austria.

Zhang, B., Li, X., Wang, T., Wang, X., 2015. Microstructure and corrosion behavior of Zr-702 joined by electron beam welding. Vacuum. 121, 159-165.Zinkle, S.J., Terrani, K.A., Gehin, J.C., Ott, L.J., 2014. Accident tolerant fuels for LWRs: A perspective. J. Nuclear Materials. 448, 374-379.

Zirker, L., 2016. Relationship of a Weld to Welding Metallurgy Causing Surface Cracks. American Welding Society, Idaho/Montana Section, Special Seminar, February 12, 2016, Idaho Falls, Idaho. 